"The Leverage Self-Delusion:

Perceived Wealth and Cognitive Sophistication"

Tiziana Assenza, Alberto Cardaci and Domenico Delli Gatti 


\title{
The Leverage Self-Delusion: Perceived Wealth and Cognitive Sophistication
}

\author{
Tiziana Assenza, Alberto Cardaci and Domenico Delli Gatti*
}

\begin{abstract}
Existing evidence suggests that individuals frequently misperceive the value of their wealth. We test the existence, and estimate sign and magnitude, of an inaccurate perception of individual net worth. By conducting a laboratory experiment, we find that most subjects perceive a given net worth as greater than its true value and this misperception increases for lower values of the leverage ratio i.e., liabilities-assets ratio. We identify an explanation relating this misperception to low cognitive sophistication and inattentive thinking. Finally, such wealth misperception predicts greater impatience, lower debt aversion and greater marginal propensities to consume out of positive (transitory) income shocks.
\end{abstract}

*Assenza: Toulouse School of Economics, University of Toulouse Capitole (tiziana.assenza@tsefr.eu); Cardaci: Goethe University Frankfurt (alberto.cardaci@hof.uni-frankfurt.de); Delli Gatti: Complexity Lab in Economics, Università Cattolica del Sacro Cuore and CESifo Group Munich, Germany (domenico.delligatti@unicatt.it). We are grateful to Marios Angeletos, William Brock, Fabrice Collard, John Duffy, Patrick Fève, Xavier Gabaix, Michael Haliassos, Per Krusell, Chen Lian, Guilherme Lichand, Víctor RíosRull, Eldar Shafir, Matthew Shapiro, Alessandro Sontuoso, Jean Tirole and numerous seminar and conference participants for helpful comments and suggestions. Tiziana Assenza acknowledges funding from ANR under grant ANR-17-EURE-0010 (Investissements d'Avenir program). Alberto Cardaci acknowledges funding from the AXA Research Fund. 


\section{Conflict-of-interest disclosure statement}

Tiziana Assenza: I have received financial support from ANR (Investissements d'Avenir program). I have nothing else to disclose.

Alberto Cardaci: I have received financial support for this project from the AXA Research Fund. I have nothing else to disclose.

Domenico Delli Gatti: I have nothing to disclose. 


\section{INTRODUCTION}

"All of our plans for the future, as individuals and as a society, hinge on our perceived wealth, and plans can be thrown into disarray if much of that wealth evaporates tomorrow."

Shiller (2015), p. 227

Individuals tend to form wrong estimates of their housing wealth (Agarwal, 2007; Corradin et al., 2017), pay limited attention to their credit card balances (Stango and Zinman, 2014) and ignore checking accounts and the liquid resources available for consumption (Morewedge et al., 2007). All in all, this suggests that they fail to have an accurate knowledge of their balance sheet and that they may incorrectly perceive the value of their total net worth to be greater or lower than its true value.

The contribution of this paper is threefold. Firstly, we investigate the existence of wealth misperception and we estimate its sign and magnitude. 1 Secondly, we explore whether this misperception relates to risk preferences, financial education and experience and cognitive sophistication. Finally, we analyze how this misperception affects individual consumption and borrowing decisions. To this end, we conduct a controlled laboratory experiment with human subjects.

We find that individuals may form inaccurate perceptions of the value of the net worth, even if they observe its true value and the value of its assets and liabilities. Moreover, the perceived value of the net worth is, on average, larger than its true value and, for a given net worth, the magnitude of the misperception depends negatively on the size of the leverage ratio, i.e. the ratio between liabilities and assets. In exploring the role of individual characteristics, we find evidence relating the presence and magnitude of wealth misperception to low levels of individual cognitive sophistication and inattentive thinking. Finally, we also find that greater misperception predicts lower debt aversion, greater impatience and a larger Marginal Propensity to Consume (MPC) out of temporary and unexpected positive income shocks.

Existing evidence suggests that the composition of a given net worth may affect how this is perceived (de Langhe and Puntoni, 2015; Sussman and Shafir, 2012). Hence, we start our experiment by testing whether people may inaccurately perceive the value of a given net worth as being greater or lower than its true value, and to what extent this misperception may relate to the level of assets and liabilities that compose it. To this end, we design two specific tasks. In the

\footnotetext{
${ }^{1}$ Although our focus is on the misperception of the net worth, for simplicity, in the text we label this phenomenon as wealth misperception.

${ }^{2}$ In Internet Appendix $\mathrm{C1}$., we introduce a standard optimal consumption choice model, enriched with a rational but inattentive agent à la Gabaix (2014), to rationalize our experimental findings.
} 
first task, subjects observe a series of pairs of balance sheet profiles of hypothetical individuals. The two profiles in each pair have the same net worth but different consolidated values of assets and debt. ${ }^{\text {亚 }}$ For each pair, we ask subjects to choose the profile that they perceive as financially superior or to state that the two profiles are financially equivalent. In the second task, subjects observe a set of ten balance sheet profiles simultaneously - all with the same net worth but different consolidated values of assets and debt — and they are asked to grade each profile from 1 to 10 based on financial superiority or to assign the same grade to all profiles that they consider equivalent.

In the presence of frictions, subjects' perceived net worth — proxied by their qualitative and quantitative evaluations of financial superiority of the balance sheet profiles in the two tasks might depend not only on the consolidated values of assets and debt, but also on their level of risk, maturity mismatching and price rigidities among others. Hence, to isolate the role of the balance sheet composition and explore whether the perceived value of a net worth may be affected exclusively by the level of assets and debt, we remove such frictions in our controlled environment. To this end, we inform subjects that assets and debt in all balance sheets are risk free, non-interest bearing and unaffected by price variations. Moreover, we clarify that all balance sheets correspond to individuals earning the same constant monthly income and having the possibility to borrow (if needed) the same amount of credit and pay the same interest rate. Finally, all financial values are perfectly observable by the subjects, so there is no role for uncertainty in making evaluations. Therefore, the level of consolidated assets and debt is the only element of variation among the balance sheet profiles in both tasks.

All in all, absent any frictions, the composition of a given net wealth should not affect perceptions, preferences and choices (Abeler and Marklein, 2017; Modigliani and Miller, 1958; Thaler, 1990). Therefore, a rational subject should perceive the two profiles in each pair of the first task as financially equivalent and assign the same grade to all profiles in the second task. However, in the first task, approximately $83 \%$ of subjects systematically perceive as superior the balance sheets with lower values of assets and debt, given net worth. In an open question about the criterion adopted for making evaluations, these subjects report that they look at the ratio between debt and assets, i.e. the leverage ratio, while subjects who perceive the profiles as equivalent ( $14 \%$ of the sample) report that they focus on the value of the net worth. We label these two groups as biased and unbiased, respectively. We also find that biased subjects assign different grades to the ten profiles in the second task. By using these grades to proxy individuals' perceived net worth for all profiles, we find that, given the true net worth, its perceived

\footnotetext{
${ }^{3}$ In our experimental instructions, liabilities are defined as debt. Hence from now on we will use the term liabilities or debt to refer to the same item.
} 
value increases for lower values of the leverage ratio. Moreover, we find that, on average, biased subjects perceive the value of the net worth from $44 \%$ to $161 \%$ larger than its true value for all ten balance sheet profiles that they observe.

In explaining these striking results, we can discard interpretations related to subjects' lack of understanding of the experiment instructions. Indeed, we find no difference in the self-reported clarity of instructions and task difficulty between biased subjects and the rest. Given the absence of frictions, subjects' answers seem scarcely attributable to risky investments, interest payments or gains, or financial uncertainty. Although, at a first sight, debt aversion might seem a suitable explanation for the choice made by biased subjects, by analyzing the answers to the final survey we find that biased agents are less debt averse than unbiased subjects. Hence, in the second part of the experiment, we test explanations related to individual characteristics.

Firstly, we elicit individual risk-aversion via the multiple price list method introduced by Holt and Laury (2002). We then evaluate subjects' financial experience by means of a simple question on credit/debit card ownership from the 2016 Survey of Consumer Finances. 4 Moreover, we exploit the different university background of the participants to test the role of financial education. Finally, we assess individual cognitive sophistication - defined as the tendency to rely on attentive and consciously deliberated thinking - by means of an incentivized version of the Cognitive Reflection Test developed by Frederick (2005).

Our analysis does not support explanations relating wealth misperception to risk preferences, financial education or experience. In fact, wealth misperception is best explained by the level of cognitive sophistication of the subjects. A lower degree of cognitive sophistication increases the probability that a subject is biased and, conditionally on being biased, it amplifies the intensity of wealth misperception. This finding provides straightforward evidence in favor of a cognitive rationale for the misperception of wealth in our experiment. Biased subjects form greater perceived values of the net worth by channeling attention towards the leverage ratio a proportional measure of balance sheet composition - rather than the true value of the net worth. This leverage self-delusion is explained by their lower level of cognitive sophistication, which induces subjects to think in proportions. $\frac{5}{5}$ Specifically, our result aligns existing evidence relating improper proportional-based heuristic thinking to lower cognitive sophistication and attention capacity (see Gillard et al., 2009 for a detailed discussion).

The recent literature in household finance highlights the importance of a correct assessment of one's own consolidated financial position for the quality of financial decisions. For example,

\footnotetext{
${ }^{4}$ Credit or debit card ownership is frequently used as a proxy for financial experience (see, e.g., Attanasio et al., 2002; Stango and Zinman, 2009).

${ }^{5}$ The fact that people form perceptual magnitudes by proportions is a well-documented finding both in economics and psychophysics (see, e.g., de Langhe and Puntoni, 2015; Weber, 2004).
} 
Carlin et al. (2019) show that providing people with consolidated information about their account balances helps to reduce their debt, interest payment and bank fees. Similarly, Levi (2015) shows that providing individuals with information on their net worth affects their consumption and saving behavior. To investigate whether the inaccurate perception of the net worth documented in our experiment predicts individuals' attitudes towards consumption and debt, we include a short survey at the end of the experiment. We find that biased subjects are more impatient and rely on debt to finance consumption and deal with a financial emergency. Conditional on being biased, a greater wealth misperception amplifies these correlations. Moreover, in a series of hypothetical scenarios, biased subjects exhibit a greater likelihood to borrow for consumption and increase spending out of temporary windfalls under balance sheet profiles that, for a given net worth, have lower leverage ratio. In fact, conditional on increasing consumption, biased subjects exhibit an MPC that is between 15\% and and 22\% larger than unbiased subjects.

The rest of the paper proceeds as follows. Section 2. provides an overview of the laboratory experiments. Section 3. describes our experimental findings, while Section 4. presents the short survey and discusses the results on the relation between wealth misperception and consumption and borrowing attitudes. Section 5. concludes.

\section{EXPERIMENT OVERVIEW}

In this section we describe our laboratory experiment, which tests whether individuals may form an inaccurate perception of a given individual net worth and perceive it as greater or lower than its true value. In particular, we study whether the direction and intensity of this misperception may relate to the composition of the net worth. To give the intuition, we explore the possibility that an individual net worth of, say, $10000 €$, can be perceived as being worth $12000 €$ or $9000 €$, depending on the level of assets and debt that compose it. To do so, we design the Profile Evaluation Task and the Profile Grading Task. To gain insights on the determinants of this misperception, we collect data on individual characteristics that have been shown to be relevant for actual wealth accumulation but have never been related to the perception of wealth, i.e. risk preferences, financial education, financial experience and cognitive abilities.

The experiment was designed using Otree (Chen et al., 2016) and run in September 2018 at Università Cattolica del Sacro Cuore in Milan (Italy). The sample consists of 93 students from the different academic programs. 6 Subjects were paid a $€ 5$ show-up fee, plus an amount related to their performance in the incentivized tasks (i.e. the Cognitive Reflection Test and the risk-aversion elicitation task). The average gain was $€ 9.38$ (std. 2.71).

\footnotetext{
${ }^{6}$ A pilot version of the experiment was run in April 2018 with 62 subjects.
} 


\subsection{Procedure}

In the Profile Evaluation Task (PET), participants are shown, in sequence, five pairs of hypothetical balance sheet profiles with identical net worth but different levels of consolidated assets and debt. ${ }^{7}$ For each pair, the participant has to choose the profile that she considers financially superior or she can state that the two profiles are financially equivalent. Figure 1 shows the interface of the task for one of the pairs. 8

\begin{tabular}{lr}
\multicolumn{2}{c}{ Mr. A } \\
\hline Assets & 32,000 \\
Liabilities & 7,350 \\
\hline Net worth & 24,650
\end{tabular}

\begin{tabular}{lr}
\multicolumn{2}{c}{ Mr. B } \\
\hline Assets & 74,800 \\
Liabilities & 50,150 \\
\hline Net worth & 24,650
\end{tabular}

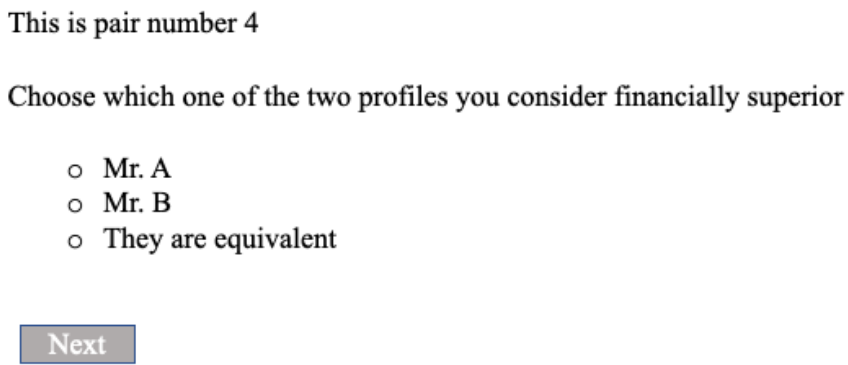

Figure 1. Interface of the Profile Evaluation Task

This figure shows the interface of the Profile Evaluation Task, for one of the five pairs of balance sheet profiles shown to the subjects. For each pair, subjects can choose one of the three answers: Mr. A, Mr. B, or They are equivalent.

To ensure that subjects' evaluation of financial superiority for the observed net worth in each pair relate exclusively to the level of assets and debt, in our controlled experiment we remove any friction that may impact subjects' assessment of the profiles. In particular, in the instructions we state explicitly that all observed values are risk free, non-interest bearing and unaffected by price variations. This allows us to neutralize the role of maturity mismatching, risk attitudes and price rigidities, respectively. Moreover, we avoid evaluations based on possible inference on labor market positions by clarifying that all profiles in each pair correspond to individuals

\footnotetext{
${ }^{7}$ The order of the pairs presented is randomized at the individual level. The level of the net worth shown to subjects in all pairs ranges between $€ 1000$ and $€ 128000$.

${ }^{8}$ The experiment was run in Italian. The interface was translated into English in Figure 1. See the Appendix for a complete copy of the instructions translated into English.
} 
earning the same constant monthly income. We also inform subjects that all profiles correspond to individuals who can borrow (if needed) at the same conditions, both in terms of interest rate and quantity of credit. Finally, given that all financial values are perfectly observable, subjects' evaluation of the profiles are not altered by uncertainty.

All in all, the level of consolidated assets and debt is the only element of variation between the two profiles in each pair. However, as it has been extensively shown (Abeler and Marklein, 2017; Modigliani and Miller, 1958; Thaler, 1990), in the absence of frictions, the composition of the net worth should not affect perceptions, preferences and choices. In fact, according to the predictions of consumer theory, a rational individual should perceive the two profiles in each pair as fungible and state that they are equivalent. Hence, formally, the Profile Evaluation Task tests the following hypothesis:

Hypothesis 1: For a given pair of financially equivalent balance-sheet profiles, with identical net worth but different levels of consolidated assets and debt, in the absence of frictions and uncertainty, subjects will state that the two profiles in each pair are financially equivalent.

Therefore, in our experiment a subject who indicates one of the two profiles as financially superior departs from the theoretical prediction and forms an inaccurate perception of the value of the net worth. In this case, the observed net worth will correspond to different perceived values and these inaccurate perceptions will depend on the balance sheet composition.

The second task is the Profile Grading Task (PGT). This aims at providing further experimental evidence that (1) can confirm or reject the existence of wealth misperception and (2) allow us to estimate its direction and intensity. In this task, subjects are simultaneously shown ten financial profiles with equal net worth but different consolidated values of assets and debt. The task consists in grading the financial superiority of each profile relative to the others, on a scale from 1 (worst off) to 10 (best off). 9 Participants are also told that they should assign the same grade to all the profiles that they consider financially equivalent. Figure 2 shows the interface of this task with some of the profiles shown to subjects.

In line with the predictions of consumer theory, a rational subject should perceive the profiles as fungible and assign the same grade to all of them. Therefore, formally, the Profile Grading Task tests the following assumption:

Hypothesis 2: For a given set of financially equivalent balance-sheet profiles, with identical net worth but different levels of consolidated assets and debt, in the absence of frictions and uncertainty, subjects will assign the same grade to all profiles.

\footnotetext{
${ }^{9}$ The evaluation occurs by moving a pointer on a bar that corresponds to the 1-10 interval. The use of the bar allows to account for the so-called digit preference, which is the tendency to round numbers to agreeable digits (Camarda et al., 2017).
} 


\begin{tabular}{ll}
\multicolumn{2}{c}{ Profile 1 } \\
\hline Assets & 54,000 \\
Liabilities & 14,800 \\
\hline Net worth & 39,200
\end{tabular}

\begin{tabular}{lr}
\multicolumn{2}{c}{ Profile 2 } \\
\hline Assets & 123,000 \\
Liabilities & 83,800 \\
\hline Net worth & 39,200
\end{tabular}

Profile 3

\begin{tabular}{lr}
\hline Assets & 41,000 \\
Liabilities & 1,800 \\
\hline Net worth & 39,200
\end{tabular}

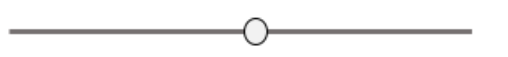

Figure 2. Interface of the Profile Grading Task

This figure shows the interface of the Profile Grading Task. Although subjects observe ten balance sheet profiles simultaneously, this figure shows only three of the profiles for the sake of simplicity. Subjects assign a grade from 1 to 10 to each profile by moving the pointer on the bar to the right of the corresponding profile.

Hence, a subject who assigns different grades to the profiles forms an inaccurate perception of the value of the net worth, whose perceived values depend on the level of assets and debt.

We then proceed to collect information on individual risk preferences, financial education, financial experience and cognitive sophistication to explore whether these individual characteristics explain the decision of the subjects in the previous tasks.

We elicit individual risk preferences by means of the multiple price list method introduced by Holt and Laury (2002). This task is structured as a game composed of ten rounds. In each round, participants have to choose between two risky options, A and B, each giving the possibility to participate in a lottery. The task is incentivized: the outcome of one of the ten chosen lotteries is randomly selected as the individual pay-off at the end of the game.10

To measure agents' financial experience we ask the following question, taken from the 2016 Survey of Consumer Finances (SCF): "Do you have at least one credit or debit card?". Credit or debit card ownership and usage has been used as a proxy for financial experience in several empirical analyses (see, e.g., Attanasio et al., 2002; Stango and Zinman, 2009). In fact, credit card ownership often correlates with learning mechanisms that increase user experience and

\footnotetext{
${ }^{10}$ Dohmen et al. (2011) finds that choices made in lotteries with real monetary incentives map into the general willingness to take risks self-reported in qualitative surveys.
} 
reduce the cost of fees (Agarwal and Mazumder, 2013).

Also financial education is widely recognized as a factor that affects the quality of individual financial decision-making (Lusardi and Tufano, 2015; van Rooij et al., 2011). Hence, to study whether it predicts subjects' tendency to form inaccurate perceptions of the net worth, we exploit the different university education background of the students in our experiment. In particular, two groups of students participated in our experiment: one was composed of students randomly selected from those enrolled in any academic program of the Faculty of Economics, conditional on having passed four courses in accounting, finance and business with a grade of at least 27/30 (being 30/30 cum laude the max grade); the other group was composed of students randomly selected from other academic programs, with no economics or finance background. All the students who were randomly selected from non-economics courses are labeled as financially uneducated.

Finally, to measure agents' cognitive sophistication and inattention, we employ an incentivized version of the Cognitive Reflection Test (CRT) first proposed by Frederick (2005). CRT is based on three questions that test the ability of the subject to override the instinctive and inattentive responses that are wrong, in favor of the more attentive and correct answers (Bosch-Rosa et al., 2018). CRT is a powerful test and a significant predictor of cognitive abilities, rational thinking and working memory (Toplak et al., 2011). The test is composed of the following three questions:11

- A bat and a ball cost $€ 1.10$. The bat costs $€ 1$ more than the ball. How much does the ball cost?

- It takes 5 machines 5 minutes to make 5 widgets. How long would it take 100 machines to make 100 widgets?

- In a lake, there is a patch of lily pads. Every day, the patch doubles in size. If it takes 48 days for the patch to cover the entire lake,how long would it take for the patch to cover half of the lake?

Subjects have 2 minutes and 30 seconds to answer each question. The agent gets one point for each correct answer. Hence, the minimum score is 0 and the maximum is 3 . We incentivize effort and attention by remunerating the subject with $€ 2$ for each point. Therefore, the minimum payoff is $€ 0$ and the maximum is $€ 6$.

\footnotetext{
${ }^{11}$ One might wonder whether the popularity of the questions included in the CRT reduces its predictive validity. However, Bialek and Pennycook (2018) show that this remains robust even after multiple exposures.
} 
To build the sample used for our analysis, we introduce two criteria. First, we define a consistency threshold for the answers reported in the Profile Evaluation Task. Based on our set-up, for each pair, subjects can state that one of the two profiles is financially superior, or that they are equivalent. If consistent, a subject would make the same choice across all pairs; if inconsistent a subject would switch multiple times from an answer to the other.12 In order to remove any effects of such inconsistent subjects from our analysis, we will consider only the sub-sample of participants who make the same choice in at least $80 \%$ of the pairs in the Profile Evaluation Task. Our second criterion introduces consistency between the answers reported in the Profile Evaluation Task and those in the Profile Grading Task. In particular, subjects who state that the profiles are equivalent in at least $80 \%$ of the pairs in the Profile Evaluation Task, should also assign the same grade to all profiles in the Profile Grading Task. Analogously, subjects choosing one profile over the other in at least $80 \%$ of the pairs of the Profile Evaluation Task, should also assign different grades to the balance sheet profiles in the Profile Grading Task.

Any individual who does not meet both the two consistency criteria described above is not included in our sample. 13 Hence, our sample includes 81 subjects, corresponding to $87.1 \%$ of the participants in the experiment.

\section{WEALTH MISPERCEPTION AND INDIVIDUAL CHARACTERISTICS}

In this section we first present the experimental results on wealth misperception, its direction and magnitude. Eventually, we assess the relation between wealth misperception and subjects' individual characteristics.

\subsection{Wealth misperception}

We use the experimental data from the Profile Evaluation Task to run an intercept-only logistic regression in order to estimate the predicted probability corresponding to the three possible outcomes: (1) stating that the two profiles in each pair are equivalent, (2) choosing the profile with higher assets and debt, (3) choosing the profile with lower assets and debt. Given the relatively small sample dimension, we proceed by means of Bayesian techniques. In particular, throughout the paper, we impose a $N(0,1)$ neutral prior on the coefficients of all the regressions

\footnotetext{
${ }^{12}$ E.g. from choosing the profile with higher assets and debt in one pair, to choosing the profile with lower assets and debt - or stating that two profiles are equivalent - in another pair.

${ }^{13}$ Only four subjects make inconsistent choices across the two tasks. See below in this Section.
} 
in our analysis. We use Markov Chain Monte Carlo (MCMC) sampling with the MetropolisHastings algorithm (Hastings, 1970; Metropolis et al., 1953) and a sample size equal to 100000.

Based on the results shown in Table 1 , there is only $15.27 \%$ probability that subjects align our Hypothesis 1 and perceive the profiles as fungible. Instead, there is a $78.33 \%$ estimated probability that subjects indicate the profiles with lower values of assets and debt as financial superior. 14

Table 1. Predicted probabilities of the choices in the Profile Evaluation Task

\begin{tabular}{cc}
\hline \hline & $\%$ \\
\hline Profiles are equivalent & 15.27 \\
& {$[13.58]$} \\
High leverage-ratio profile & 6.40 \\
& {$[3.70]$} \\
Low leverage-ratio profile & 78.33 \\
& {$[82.72]$} \\
\hline
\end{tabular}

Notes. Acceptance rate: 0.4333; average efficiency rate: 0.225 . Values in brackets represent the actual sample distribution across choices.

To shed some light on the pervasiveness of this behavior, we analyze subjects' answers to an open question presented at the end of the task. This asks subjects to clarify the criterion adopted in making profile evaluations. A simple text analysis reveals that about $72 \%$ of subjects who choose profiles with lower assets and debt base their evaluations on the leverage ratio (i.e. the ratio between debt and assets) of each profile. In fact, the logistic regression in column 1 of Table 2 shows that making evaluations based on the leverage ratio increases the probability of choosing the profiles with lower assets and debt by 16.94 percentage points. Making evaluations based on the net worth, instead, decreases the same probability by 23.50 percentage points (column 2). These results are robust to the inclusion of our measures of financial education and financial experience. In fact, Table 2 shows that marginal effects are strongly stable across all set of regressions.

The results above unveil the presence of a pervasive wealth perception bias characterized by a tendency to form inaccurate perceptions of a given net worth value based on its composition. Specifically, the vast majority of subjects in our sample perceive a given net worth as financially superior for lower values of the leverage ratio. Hence, we are able to identify two groups of subjects:

\footnotetext{
${ }^{14}$ To verify whether subjects answers are affected by the framing of the task or computational difficulties, we include two pairs in which the value of one, between assets and debt, is hidden in both profiles. With the exception of two subjects, all subjects in the sample make choices that are consistent with the rest of the task. This suggests that the pattern of choices is robust to the framing of the problem and computational difficulties.
} 
TAble 2. Profile Choice AND Reported CRITERION

\begin{tabular}{|c|c|c|c|c|c|c|}
\hline & (1) & (2) & (3) & (4) & (5) & (6) \\
\hline Leverage ratio & 0.1694 & & 0.0819 & 0.0852 & 0.0854 & 0.0808 \\
\hline & {$[0.1355 ; 0.1974]$} & & {$[0.0577 ; 0.1037]$} & {$[0.0605 ; 0.1075]$} & {$[0.0605 ; 0.1078]$} & {$[0.0547 ; 0.1037]$} \\
\hline Net worth & & -0.2350 & -0.1963 & -0.1964 & -0.1937 & -0.1981 \\
\hline & & {$[-0.2573 ;-0.2058]$} & {$[-0.2147 ;-0.1698]$} & {$[-0.2148 ;-0.1703]$} & {$[-0.2120 ;-0.1682]$} & {$[-0.2177 ;-0.1711]$} \\
\hline Financial education & & & & 0.0124 & & 0.0065 \\
\hline & & & & {$[-0.0103 ; 0.0345]$} & & {$[-0.0273 ; 0.0136]$} \\
\hline Financial experience & & & & & 0.0033 & 0.0278 \\
\hline & & & & & {$[-0.0236 ; 0.0336]$} & {$[-0.0529 ; 0.0015]$} \\
\hline Controls & Yes & Yes & Yes & Yes & Yes & Yes \\
\hline Sample size & 78 & 78 & 78 & 78 & 78 & 78 \\
\hline
\end{tabular}

Notes. Bayesian logistic regression of a dummy equal to 1 if the subject chooses the profiles with lower assets and debt, over a dummy equal to 1 if the subject reports looking at the leverage ratio (columns 1 and 3 to 6 ), a dummy equal to 1 if the subject reports looking at the net worth (columns 2 to 6 ), a dummy equal to 1 if the subject is financially educated (columns 4 and 6 ) and a dummy equal to 1 if the subject has a credit card (columns 5 and 6 ). Controls include age, gender dummy, family size and family education level as covariates. Values in brackets are $68 \%$ Highest Posterior Density Intervals.

- Unbiased subjects: they correctly perceive financially equivalent balance sheet profiles as fungible regardless of their composition (column 1 in Table 1). These subjects align the theoretical predictions and have a correct perception of the value of a net worth.

- Biased subjects: they do not perceive financially equivalent balance sheet profiles as fungible. These subjects depart from the theoretical prescriptions and perceive the value of a given net worth as greater when the leverage ratio is lower (column 3 in Table 1).

In the rest of the paper, we will focus our analysis on these two groups, thus excluding from the sample those subjects who choose the profiles with higher leverage ratio, as they represent only $3.7 \%$ of our sample (column 2 in Table 1 ).

Contrary to the prediction of Hypothesis 2, by analyzing subjects' answers in the Profile Grading Task we find that, on average, biased subjects assign different grades to nine of the ten profiles, while all unbiased subjects assign the same grade to all profiles. 15 Specifically, as shown in Table 3, an increase in the leverage ratio by one percentage point results in a reduction in the average grade assigned by biased subjects of roughly 0.75 .16

The result from the Profile Grading Task confirms and strengthens the finding from the previous task: for a given net worth, the size of the leverage ratio and the perceived value of the net worth are negatively correlated. However, we do not know whether such perceived value is greater or lower than the true net worth value observed by the subjects, and by how much. Our

\footnotetext{
${ }^{15}$ This is not surprising: given the two consistency criteria described in the previous section, all subjects who do not perceive the profiles in the Profile Evaluation Task as fungible, should assign different grades to at least two profiles in the Profile Grading Task.

${ }^{16}$ For the purpose of this regression we centralize and normalize the data.
} 
Table 3. Average grades and leverage ratio

\begin{tabular}{ll}
\hline Mean & -0.7571
\end{tabular}

$[-0.9811 ;-0.5479]$

Notes. Bayesian OLS regression of average grades over the leverage ratio. Acceptance rate: 0.4069 ; average efficiency rate: 0.5375 . Values in brackets are $68 \%$ Highest Posterior Density Intervals.

goal in the next section is to estimate the direction and magnitude of such perceived value. In fact, as subjects observe ten profiles with the same net worth but different levels of assets and debt, there exist ten different values of the leverage ratio and, possibly, ten different perceived values of the same net worth.

\subsection{Wealth perception bias: Intensity and direction}

To assess the direction and intensity of the subjects' misperception of the net worth, we exploit the data from the Profile Grading Task and we introduce a measure that we call bias degree, $b_{i}^{j}$. This is defined as follows:

$$
b_{i}^{j}=\frac{P W_{i}^{j}}{N W}
$$

where $N W$ is the true net worth (homogeneous across all balance sheet profiles) and $P W_{i}^{j}$ is subject $i$ 's perceived wealth for profile $j$, with $j=[1,10]$. Any value of $b_{i}^{j}$ higher (lower) than 1 indicates that, for subject $i$, profile $j$ corresponds to a level of perceived wealth that is higher (lower) than the true net worth. Moreover, a greater distance from one implies a larger deviation of perceived wealth from the true value of the net worth. Therefore, the bias degree measures both the direction and the intensity of the wealth misperception. Finally, notice that, since unbiased subjects have a level of perceived wealth that corresponds to the true value of the net worth, their $b_{i}^{j}$ equals 1 for any profile $j$.

Although $P W_{i}^{j}$ is not directly observed in our experiment, we can estimate the bias degree in Equation 1 by using individual grades in the Profile Grading Task, which represent a proxy for the level of wealth attached to each balance sheet profile. In particular:

$$
b_{i}^{j}=\frac{P W_{i}^{j}}{N W}=g_{i}^{j} \bar{g}
$$

where $g_{i}^{j}$ is the grade assigned by biased subject $i$ to the balance sheet profile $j$ and $\bar{g}$ is the expected value of $1 / g_{u}$, with $g_{u}$ being the grade assigned by unbiased subjects $(u=1, \ldots, U)$ 
to all balance sheet profiles. Therefore, for each profile $j$, the estimated bias degree is equal to the mean of the ratios between the grade assigned by biased agent $i$ and the grades assigned by each unbiased subject $u .17$

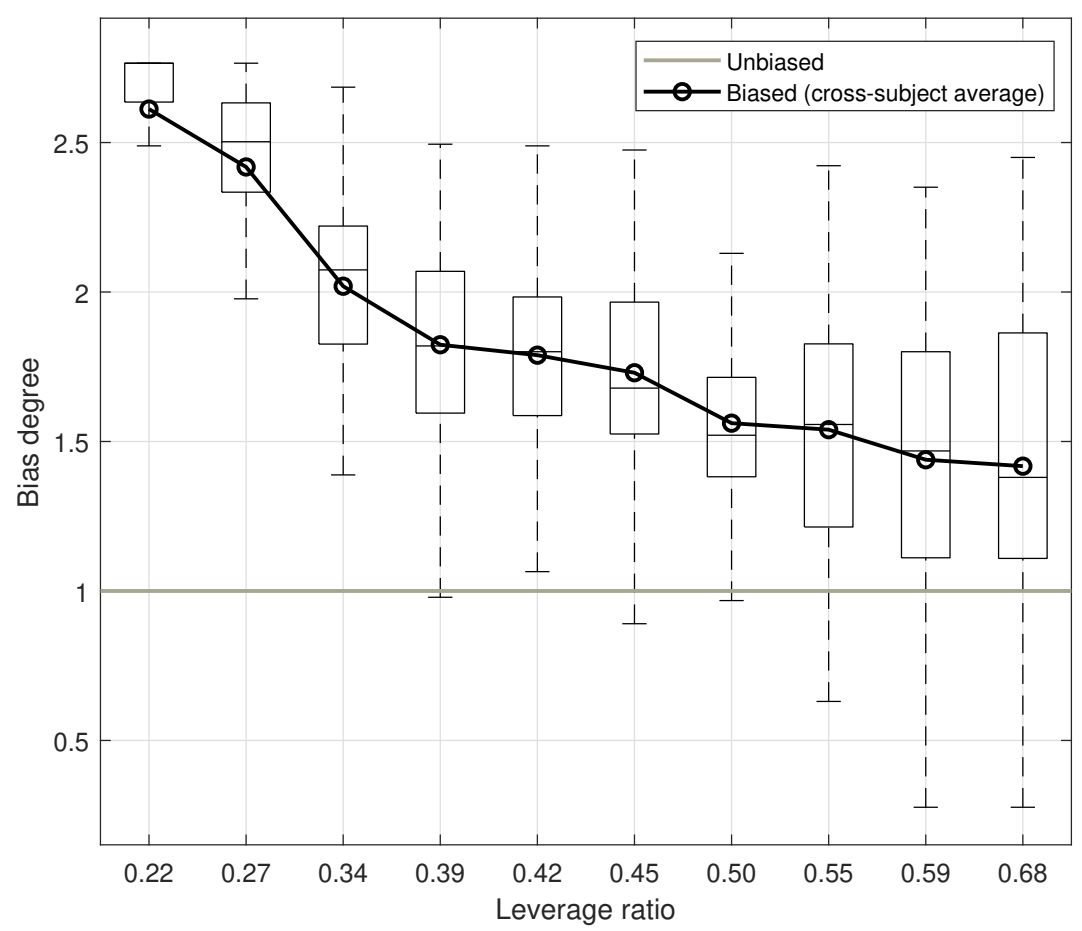

Figure 3. Bias Degree AND LeVERAge RATIO

This figure shows the distribution (box plot) of the bias degree in Equation 2 across biased subjects, for each of the ten balance sheet profiles shown in the Profile Grading Task. The black line is the mean of the distribution, i.e. the cross-subject average bias degree. The gray line represents the bias degree for unbiased subjects, which is equal to 1 , as their perceived wealth equals the true value of the net worth for any balance sheet profile. The X-axis reports the leverage ratio - defined as debt over assets - of each balance sheet profile.

In Figure 3 we show the distribution of the bias degree across biased subjects for each of the ten balance sheet profiles in the Profile Grading Task. The black line represents the mean of the distribution, that is the cross-subject average degree. This ranges from 1.44, for the highest leverage ratio, to 2.61 , for the lowest leverage ratio, thus implying that the perceived value of the net worth is, on average, between $44 \%$ and $161 \%$ larger than the true value of the net worth. Hence, on average, biased subjects perceive the net worth as larger than its true value for all the profiles that they observe but the intensity of such misperception decreases for higher values of

\footnotetext{
${ }^{17}$ In fact, by definition, $\bar{g}=\frac{1}{U} \sum_{u=1}^{U} \frac{1}{g_{u}}$. This measure reduces the effect of the heterogeneity of the grades assigned by unbiased subjects.
} 
the leverage ratio. In fact, Table 4 shows that an increase in the leverage ratio by one percentage point results in a reduction in the cross-subject average degree of roughly 0.31 .

TABle 4. Bias degree AND LeVerage RATio

\begin{tabular}{lc}
\hline \hline Mean & 0.3101 \\
& {$[0.0152 ; 0.6232]$}
\end{tabular}

Notes. Bayesian OLS regression of the bias degree over the leverage ratio. Acceptance rate: 0.389; average efficiency rate: 0.255 . Values in brackets are $68 \%$ Highest Posterior Density Intervals.

Summing up, our results on the perception of wealth show that biased subjects - the vast majority of our sample - exhibit a systematic tendency to form inaccurate perceptions of a given net worth, despite the absence of frictions and uncertainty. This misperception relates to the size of the leverage ratio. In particular, although biased subjects tend to perceive the value of the net worth as greater than its true value for any balance sheet profile that they observe, the magnitude of the misperception increases markedly for lower values of the leverage ratio. In fact, this result shows that biased subjects are very sensitive to the leverage ratio - a proportional measure of the balance sheet composition - rather than the net worth - an absolute measure. However, this propensity to focus on the leverage ratio is flawed, since the characteristics of our set-up make the balance sheet profiles fungible. So, how to explain the choices made by these subjects?

We discard explanations related to lack of understanding of the experimental instructions and procedures. Indeed, all subjects must successfully complete a sequence of control questions before performing the Profile Evaluation Task and the Profile Grading Task. Moreover, we ask all subjects to grade the clarity of the instructions, as well as the difficulty of the two tasks, but find no meaningful difference in either measure between the groups of biased and unbiased subjects. In addition, the absence of frictions in our experiment allows to rule out explanations relating the wealth misperception found in the experiment to risky investments, interest payments or gains, or financial uncertainty. Finally, we can also dismiss interpretations relating biased subjects' choices to greater debt aversion: the results from the survey on attitudes towards debt in Section 4. show that biased subjects are substantially less debt averse than unbiased subjects.

Our results provide suggestive evidence in favor of a psychological interpretation of the choices made by biased subjects in the first two tasks. In particular, the pervasive wealth misperception in our sample seems related to a widespread tendency to rely on proportional thinking even in a context in which this is inappropriate. This leads biased subjects to form an imperfect perception of wealth by channeling attention towards an "improper" measure of the balance 
sheet composition, i.e. the leverage ratio. This interpretation aligns existing evidence in psychology and economics showing that individuals often tend to rely on proportional reasoning (de Langhe and Puntoni, 2015; Friedrich et al., 2005), even in situations when this is inadequate (see, e.g., Gillard et al., 2009). In the next section we test a cognitive underpinning that may corroborate our interpretation, as well as alternative explanations for the presence of the wealth perception bias, its direction and intensity.

\subsection{The role of individual characteristics}

Table 5. Behavioral Predictors

\begin{tabular}{lcccc}
\hline \hline & $(1)$ & $(2)$ & $(3)$ & $(4)$ \\
& Bias & $P(M \mid Y)$ & Degree & $P(M \mid Y)$ \\
\hline Model (1) - Risk aversion & 0.0063 & 0.0212 & -0.0259 & 0.0000 \\
Model (2) - Financial experience & {$[-0.0054 ; 0.0093]$} & & {$[-0.0393 ;-0.0104]$} & \\
& 0.0165 & 0.1073 & -0.0470 & 0.0000 \\
Model (3) - Financial education & {$[-0.0212 ; 0.0540]$} & & {$[-0.1565 ; 0.0656]$} & \\
& 0.0143 & 0.0885 & 0.0253 & 0.0000 \\
Model (4) - CRT score & {$[-0.0083 ; 0.0441]$} & & {$[-0.0362 ; 0.0846]$} & 1.0000 \\
Controls & -0.0682 & 0.7830 & -0.1404 & \\
Sample size & {$[-0.0805 ;-0.0551]$} & & {$[-0.1645 ;-0.1166]$} & \\
\hline Not Cos & Yes & & Yes & \\
\hline
\end{tabular}

Notes. Column (1): marginal effects from a Bayesian logistic regression of a dummy (Bias) equal to 1 if the subject is biased on the number of safe choices in the risk aversion elicitation task (Model 1), a dummy equal to 1 if the subject has credit/debit card (Model 2), a dummy equal to 1 if the subject is financially educated (Model 3) and CRT score (Model 4). Column (3): coefficients from a Bayesian OLS regression of the individual average bias degree (Degree) on the same four variables. Controls include age, gender dummy, family size and family education level as covariates. Values in brackets are 68\% Highest Posterior Density Intervals. Column (2) and (4): posterior probability $(P(M \mid Y))$ of the for models for both Bias and Degree; prior probability for each model: 0.25 .

In column 1 of Table 5 we report the marginal effects from four regression models of Bias - a dummy equal to 1 if the subject is biased - on risk aversion, financial experience, financial education and CRT score. Column 3 reports the coefficients from four regressions of the individual average bias degree on the same variables. For each of these models, we also compute their posterior probability (columns 2 and 4), given the observed experimental data, under the assumption that all of them are equally likely a priori. For both Bias and Degree, we find that the regression model with CRT score is substantially more likely, as it has a very large posterior probability of $78.30 \%$ and $100 \%$, respectively. The credible intervals for the marginal effects of both variables corroborate these results. In addition, the marginal effects show that the level of 
cognitive sophistication, measured by the score in the Cognitive Reflection Test, has the largest effect over the probability of being biased and, conditionally on being biased, on the intensity of the wealth misperception. In fact, the results reported in Table 6 show that unbiased subjects have an average CRT score equal to 1.81 , compared to 0.91 of the biased group. We also report the within-group distribution of subjects: the percentage of subjects answering 0 correct questions is much larger in the biased group (47.76\%), while the percentage of subjects obtaining the highest score, thus providing all correct answers, is substantially greater within the unbiased group (45.45\%).

TABle 6. Scores in CRT

\begin{tabular}{lccccc}
\hline \hline & Average score & \multicolumn{4}{c}{ Correct answers (\%) } \\
& & 0 & 1 & 2 & 3 \\
\hline \multirow{2}{*}{ Biased } & 0.91 & 47.76 & 22.39 & 20.90 & 8.96 \\
& {$[1.02]$} & & & & \\
\multirow{2}{*}{ Unbiased } & 1.81 & 18.18 & 27.27 & 9.09 & 45.45 \\
& {$[1.25]$} & & & & \\
\hline
\end{tabular}

Notes. Average score (standard deviation in brackets) and distribution of subjects per correct answers in the Cognitive Reflection Test (CRT).

Finally, in Figure 4 we provide a visualization of these results. We show that, while the cross-subject average bias degree decreases in the leverage ratio independently of the size of the CRT score, the bias degree is systematically greater for agents with lower CRT score. In other words, the intensity of the wealth misperception is substantially larger among biased subjects with lower cognitive sophistication.

The intuition for our results is straightforward and supports a cognitive rationale for the misperception of wealth, rather than interpretations related to risk preferences, financial experience or education. To adopt the categorization of Dual Process Theory (Kahneman, 2003a,b; Stanovich and West, 2003), our results suggest that the behavior of biased subjects is correlated with a tendency to rely on System 1, i.e. a more automatic and heuristic-based type of thinking, which consumes a lower amount of attentional resources (Kihlstrom, 1987; Moritz et al., 2014). 18 Existing evidence in psychology shows that System 1 thinkers are generally more likely to rely on proportional reasoning also in contexts where this is improper (see Gillard et al., 2009

\footnotetext{
${ }^{18}$ In general, the literature in psychology highlights the existence of a significantly positive correlation between a variety of measures of individual cognitive abilities and attention of different types (see, among others, Allred et al., 2016; Barrett et al., 2004; Ben-Shakhar and Sheffer, 2001; Dukas, 2004). In fact, attentional neglects can often explain the poor performance in cognitive sophistication tasks (Allred et al., 2016; Dukas, 2004).
} 


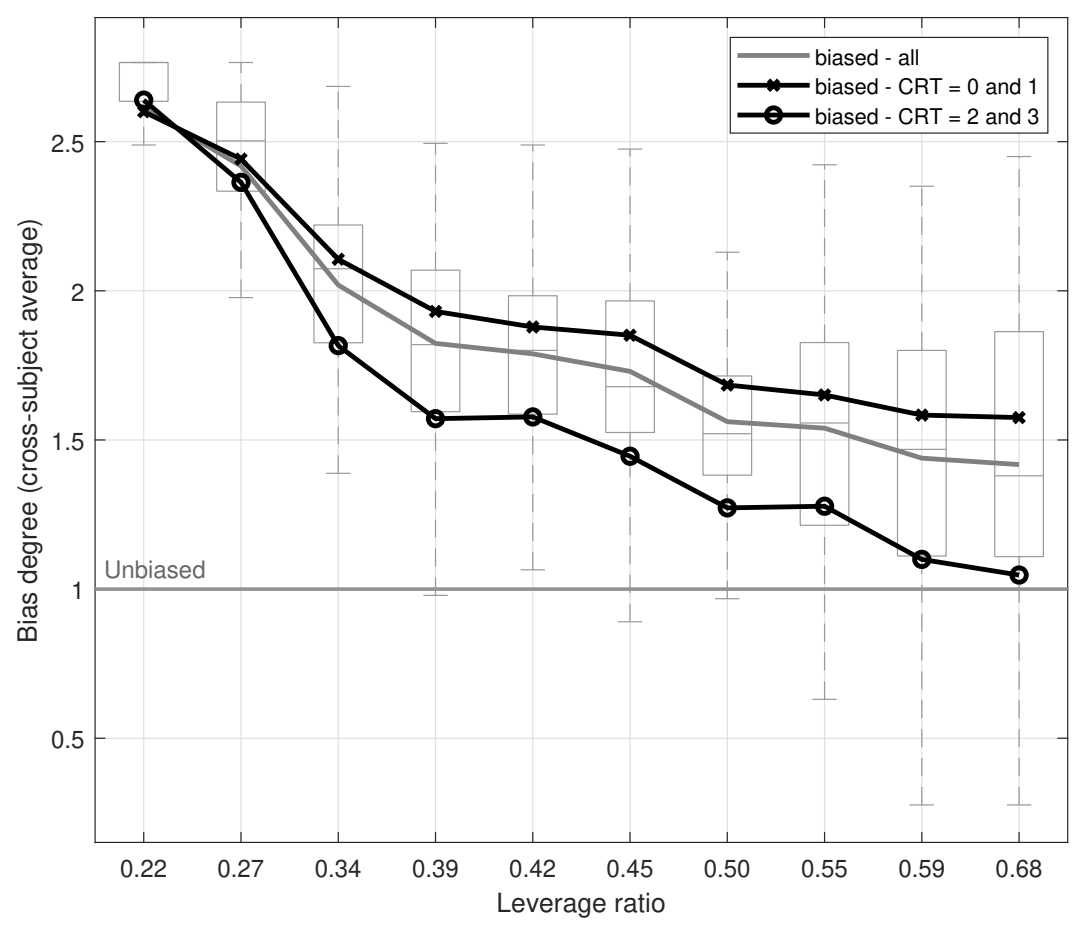

FiguRE 4. BiAs DEGREE AND CRT SCORES

This figure shows the distribution (box plot) of the bias degree in Equation 2 across biased subjects, for each of the ten balance sheet profiles shown in the Profile Grading Task. The gray line is the mean of the distribution, or the cross-subject average bias degree. The two black lines represent the cross-subject average bias degree for two sub-groups of biased subjects: biased subjects with low CRT score - i.e. CRT score equal to 0 and $1-$ and biased subjects with high CRT score -i.e. CRT score equal to 2 and 3. The horizontal gray line represents the bias degree for unbiased subjects, which is equal to 1 , as their perceived wealth equals the true value of the net worth for any balance sheet profile. The $\mathrm{X}$-axis reports the leverage ratio - defined as debt over assets - of each balance sheet profile.

for a detailed discussion). In the context of our experiment, biased subjects are System 1 thinkers who, indeed, exhibit a tendency to rely on proportional thinking and form perceived values of the net worth by channeling attention towards the leverage ratio, rather than the net worth.

\section{WEALTH MISPERCEPTION: CONSUMPTION AND DEBT DECISIONS}

In the final part of the experiment we include a short survey to assess the relation between the presence of wealth perception, its intensity and subjects' consumption and debt decisions. In the following, for the sake of discussion we divide the set of questions into two groups: those related to consumption behavior and those related to attitudes toward debt.19

\footnotetext{
${ }^{19}$ The Appendix contains the complete list of questions presented in the survey.
} 


\subsection{Consumption}

The first question investigates individuals' attitudes towards savings and time preferences. In particular, following Parker (2017), we ask subjects whether they self identify as "the type of person that prefers to spend money and enjoy it today or save more for the future", with a binary choice: "spend now" and "save for the future". 20

We then study consumption decisions out of unexpected and transitory positive income shocks, both in general and under given balance-sheet profiles. In particular, we modify the question introduced by Fuster et al. (2020) to describe a hypothetical scenario in which subjects unexpectedly receive a one-time payment and they are asked to indicate what they would do in the following month. Agents can choose among three options: i) they can increase spending more than if they had not received the payment; ii) they can decrease spending; or iii) they can keep it unchanged. Compared to Fuster et al. (2020), we repeat the question only twice: first, with a $500 €$ payment; then, with $5000 €$. Moreover, in order to test whether and how the inaccurate perception of a net worth affects the likelihood to increase spending, we introduce a third question with a $500 €$ payment, in which each subject is shown two financial profiles with identical net worth but different composition in terms of the consolidated level of assets and debt. Subjects are asked to state under which of the two profiles they would be more likely to increase their expenses in the following month. They also have the possibility to state that they would increase their expenses in either, or neither, case. If greater perceived wealth were linked to a higher likelihood to increase spending out of unexpected positive gains, biased subjects should choose the profile corresponding to a lower leverage ratio, while unbiased subjects should make a decision that, given the value of net worth, does not depend on the composition of the balance sheet. In all three questions, subjects who would increase their expenses are asked the exact amount. Similarly to Fuster et al. (2020), this allows us to estimate marginal propensities to consume.

Table 7 reports the results of a series of regressions of the responses to the consumption questions on Bias and Degree.21 We find the following results.

a. A large majority of biased subjects report being the type of person that is more prone to spend and enjoy the present, while the majority of unbiased subjects self-identify as

\footnotetext{
${ }^{20}$ Parker (2017) uses this question in a survey as a proxy of the patience/impatience of the subjects. He shows that answers to this question strongly predict consumption behavior, in that people who report being "spenders" do not smooth consumption and have a significantly larger spending response to predictable lump-sum payments, compared to people who self-identify as "savers".

${ }^{21}$ Bias and Degree take the same definition as in the previous section. The distribution of subjects for each question is reported in Appendix B.
} 
Table 7. Effect of Wealth Perception Bias and Bias Degree on Consumption attitudes

\begin{tabular}{|c|c|c|}
\hline & $\begin{array}{l}(1) \\
\text { Bias }\end{array}$ & $\begin{array}{c}(2) \\
\text { Degree }\end{array}$ \\
\hline \multicolumn{3}{|c|}{ Panel A - Impatience } \\
\hline & $\begin{array}{c}0.2924 \\
{[0.2409 ; 0.3547]}\end{array}$ & $\begin{array}{c}0.1234 \\
{[0.0847 ; 0.1924]}\end{array}$ \\
\hline \multicolumn{3}{|c|}{ Panel $B$ - Spending response (500€) } \\
\hline Less & $\begin{array}{c}0.0144 \\
{[-0.0053 ; 0.0415]}\end{array}$ & $\begin{array}{c}0.0049 \\
{[0.0044 ; 0.0228]}\end{array}$ \\
\hline Same & $\begin{array}{c}-0.2036 \\
{[-0.2561 ;-0.1581]}\end{array}$ & $\begin{array}{c}-0.1057 \\
{[-0.1474 ;-0.1000]}\end{array}$ \\
\hline More & $\begin{array}{c}0.2124 \\
{[0.1694 ; 0.2639]}\end{array}$ & $\begin{array}{c}0.1357 \\
{[0.1253 ; 0.1707]}\end{array}$ \\
\hline \multicolumn{3}{|c|}{ Panel $C-$ Spending response $(5000 €)$} \\
\hline Less & $\begin{array}{c}-0.0205 \\
{[-0.0353 ; 0.0111]}\end{array}$ & $\begin{array}{c}-0.0286 \\
{[-0.0239 ; 0.0177]}\end{array}$ \\
\hline Same & $\begin{array}{c}-0.0503 \\
{[-0.1115 ; 0.0155]}\end{array}$ & $\begin{array}{c}0.0143 \\
{[-0.0287 ; 0.0862]}\end{array}$ \\
\hline More & $\begin{array}{c}0.0674 \\
{[0.0086 ; 0.1265]}\end{array}$ & $\begin{array}{c}0.0149 \\
{[-0.0529 ; 0.0610]}\end{array}$ \\
\hline \multicolumn{3}{|c|}{ Panel D - Profile type } \\
\hline Low-Ratio Profile & $\begin{array}{c}0.3810 \\
{[0.3292 ; 0.4443]}\end{array}$ & $\begin{array}{c}0.1655 \\
{[0.0918 ; 0.2524]}\end{array}$ \\
\hline High-Ratio Profile & $\begin{array}{c}-0.0585 \\
{[-0.0796 ;-0.0167]}\end{array}$ & $\begin{array}{c}-0.1211 \\
{[-0.1641 ;-0.0146]}\end{array}$ \\
\hline Neutral & $\begin{array}{c}-0.3311 \\
{[-0.3830 ;-0.2818]}\end{array}$ & $\begin{array}{c}-0.0466 \\
{[-0.0920 ; 0.0245]}\end{array}$ \\
\hline Controls & Yes & Yes \\
\hline Sample size & 78 & 67 \\
\hline
\end{tabular}

Notes. (1): Marginal effects from Bayesian logistic and multinomial logistic regressions of the answers to the consumption questions on a dummy equal to 1 if the subject is biased. (2): Coefficients from Bayesian OLS regressions of the answers to the consumption questions on the average bias degree. Controls: age, gender dummy, family size and family education level. Values in brackets are 68\% Highest Posterior Density Intervals.

savers. In fact, the presence of the wealth perception bias corresponds to a 29 percentage points increase in the probability of being an impatient type of person. Moreover, conditional on being biased, an increase in the average bias degree by 1 corresponds to a 12 percentage points increase in the probability of being impatient.

b. Biased subjects are generally more prone to increase spending out of an unexpected and transitory positive income shock compared to unbiased ones, both in the $500 €$ scenario 
and in the $5000 € 22$ In addition, conditional on being biased, an increase in the average bias degree by 1 corresponds to a 14 percentage points increase in the probability of spending more in the $500 €$ scenario. Finally, we also find that the point estimates of the average Marginal Propensity to Consume (MPC), conditional on spending more, are equal to 0.39 and 0.32 for biased and unbiased subjects respectively, in the $500 €$ scenario, and 0.23 and 0.20 , in the $5000 €$ scenario. Therefore, biased subjects exhibit a more pronounced reaction to unexpected and transitory positive income shocks, with a MPC that is between $15 \%$ (in the $5000 €$ scenario) and $21.88 \%$ higher (in the $500 €$ scenario) than unbiased subjects, thus suggesting lower consumption smoothing compared to unbiased subjects.

c. Biased subjects are much more likely to increase their expenses under the lower leverageratio profile, while a large majority of unbiased subjects is neutral to the leverage ratio. The presence of the wealth perception bias, indeed, increases the probability that a biased subject increases consumption under the lower leverage-ratio profile by 38 percentage points. The intuition is straightforward: a lower leverage ratio implies a greater value of perceived wealth, which leads to a higher likelihood to increase spending. Moreover, an increase in the bias degree by 1 corresponds to a 16 percentage point increase in the probability that biased subjects increase consumption under the lower leverage-ratio profile.

\subsection{Debt}

We start by evaluating attitudes towards debt, with a focus on consumer credit. In particular, we rely on a question from the 2016 Survey of Consumer Finances by asking subjects whether they think it is a good idea to finance expenses by borrowing. There are three possible answers: "Good idea", "Good in some ways, bad in others" and "Bad idea".23

We, then, investigate subjects' choices when they face financial difficulties. In particular, we introduce the following question: "If tomorrow you experienced a financial emergency that left you unable to pay all of your bills, how would you deal with it?" The set of possible answers includes "borrow money", "spend out of savings", "postpone payments" and "cut back".24

\footnotetext{
${ }^{22}$ However, when we increase the amount of the windfall from $500 €$ to $5000 €$, the share of subjects who would increase their consumption rises in both groups, with a larger increase for unbiased subjects, thus narrowing the gap between the two groups. This result is in line with the findings by Fuster et al. (2020), who finds a size effect which leads respondents to be more willing to increase spending when the size of the windfall increases.

${ }^{23}$ Even though this question does not allow to discriminate among different types of debt, it is generally considered a good proxy of personal attitudes towards the use of borrowing for consumption and it has been used as a measure of debt aversion in other works (see, e.g. Chien and Devaney, 2001; Stango and Zinman, 2009).

${ }^{24}$ Although the answer "borrow money" does not mention a specific type of loan, it has been shown that people
} 
Finally, we assess willingness to take on debt for consumption, by including a question that draws on the so-called "reported preference" approach (Fuster et al., 2020; Parker and Souleles, 2017). This relies on reported changes in borrowing (or spending) in hypothetical scenarios, elicited by means of survey questions, thus allowing a great amount of flexibility in treatment design (Fuster et al., 2020). 25 In particular, we present a hypothetical situation in which subjects have to buy a product but, due to the lack of liquid assets, they have to borrow. Moreover, we show subjects two financial profiles with identical net worth but different composition in terms of the consolidated level of assets and debt. We ask them to state under which of the two profiles they would be more likely to borrow $450 €$ to buy a consumption good (a new television). They can also state that they would borrow under either or neither profile. This allows us to identify either aversion to debt (not borrowing under any profile) or neutrality to the balance sheet composition (borrowing under any profile).

Table 8 reports the results of a series of regressions of the responses to the questions on debt attitudes on Bias and Degree.26 We find the following results.

a. Biased subjects are more comfortable with the idea of debt-financed consumption. In fact, being biased reduces the probability of being debt averse by roughly 20 percentage points, while increasing the probability of being debt seeker by 21 percentage points. In addition, an increase by 1 in the bias degree decreases the probability of being debt averse by roughly 14 percentage points, while increasing the probability of being debt seeker by 11 percentage points.

b. Such comfort with the use of debt extends also to the context of a financial emergency. A large majority of biased subjects feel at ease with the idea of using debt to cope with the necessity of paying overdue bills, while most of unbiased subjects choose to use their savings or to cut other expenses. Indeed, the presence of the wealth perception bias increases the likelihood to rely on debt as a means to cope with a financial emergency by

who find themselves in a cash crunch often tend to make unsound financial decisions by relying on payday loans and other expensive forms of unsecured credit (see e.g. Bertrand and Morse, 2011; Mullainathan and Shafir, 2014).

${ }^{25} \mathrm{An}$ important remark has to do with the following concern: Do reported preferences have little informative content as to what individuals would do if faced with actual decisions to borrow (or spend)? Fuster et al. (2020) point to the comprehensive analysis carried out by Parker and Souleles (2017) and Parker et al. (2013): the former show that comparing reported consumption responses to hypothetical tax rebates with actual spending responses from past tax rebates, produces very little differences; the latter, found that reported preferences match actual behavior, in that subjects who reported spending their 2008 fiscal stimulus payment did in fact do so. These considerations support the idea that reported preferences in hypothetical scenarios may provide significant indications of individual behavior in actual decision-making contexts.

${ }^{26}$ The distribution of subjects for each question is reported in Appendix B 
Table 8. Effect of Wealth Perception Bias and Bias Degree on borrowing attitudes

\begin{tabular}{|c|c|c|}
\hline & $\begin{array}{l}1) \\
\text { Bias }\end{array}$ & $\begin{array}{c}(2) \\
\text { Degree }\end{array}$ \\
\hline \multicolumn{3}{|c|}{ Panel $A$ - Debt attitude } \\
\hline Averse & $\begin{array}{c}-0.2046 \\
{[-0.2626 ;-0.1367]}\end{array}$ & $\begin{array}{c}-0.1391 \\
{[-0.2123 ;-0.0521]}\end{array}$ \\
\hline Seeker & $\begin{array}{c}0.2145 \\
{[0.1730 ; 0.2675]}\end{array}$ & $\begin{array}{c}0.1084 \\
{[0.1000 ; 0.1352]}\end{array}$ \\
\hline Neutral & $\begin{array}{c}-0.0308 \\
{[-0.0854 ; 0.0192]}\end{array}$ & $\begin{array}{c}0.0321 \\
{[-0.0359 ; 0.0926]}\end{array}$ \\
\hline \multicolumn{3}{|c|}{ Panel B - Financial emergency response } \\
\hline Borrow & $\begin{array}{c}0.2568 \\
{[0.2162 ; 0.3128]}\end{array}$ & $\begin{array}{c}0.1493 \\
{[0.1341 ; 0.1717]}\end{array}$ \\
\hline Use savings & $\begin{array}{c}-0.1423 \\
{[-0.1888 ;-0.0813]}\end{array}$ & $\begin{array}{c}-0.0110 \\
{[-0.0114 ; 0.0440]}\end{array}$ \\
\hline Postpone & $\begin{array}{c}-0.0323 \\
{[-0.0559 ; 0.0100]}\end{array}$ & $\begin{array}{c}-0.0214 \\
{[-0.0157 ; 0.0241]}\end{array}$ \\
\hline Cut & $\begin{array}{c}-0.0573 \\
{[-0.1157 ; 0.0043]}\end{array}$ & $\begin{array}{c}-0.0934 \\
{[-0.1705 ;-0.0480]}\end{array}$ \\
\hline Other & $\begin{array}{c}-0.0261 \\
{[-0.0342 ;-0.0040]}\end{array}$ & $\begin{array}{c}-0.0038 \\
{[-0.0018 ; 0.0097]}\end{array}$ \\
\hline \multicolumn{3}{|c|}{ Panel $C$ - Borrowing for consumption } \\
\hline Low-ratio profile & $\begin{array}{c}0.4901 \\
{[0.4437 ; 0.5483]}\end{array}$ & $\begin{array}{c}0.2964 \\
{[0.2779 ; 0.3404]}\end{array}$ \\
\hline High-ratio profile & $\begin{array}{c}-0.4415 \\
{[-0.4942 ;-0.3958]}\end{array}$ & $\begin{array}{c}-0.1051 \\
{[-0.1320 ;-0.0199]}\end{array}$ \\
\hline Neutral & $\begin{array}{c}-0.0337 \\
{[-0.0429 ;-0.0068]}\end{array}$ & $\begin{array}{c}-0.1391 \\
{[-0.2194 ;-0.0715]}\end{array}$ \\
\hline Controls & Yes & Yes \\
\hline Sample size & 78 & 67 \\
\hline
\end{tabular}

Notes. (1): Marginal effects from Bayesian logistic regressions of the measures of debt attitudes on a dummy equal to 1 if the subject is biased. (2): Coefficients from Bayesian OLS regressions of debt variables on the average bias degree. Controls: age, gender dummy, family size and family education level. Values in brackets are $68 \%$ Highest Posterior Density Intervals.

roughly 26 percentage points. Finally, conditional on being biased, a greater bias degree amplifies the tendency to borrow as a means to cope with a financial emergency.

c. For a given net worth, a large majority of biased subjects favor borrowing under the lower leverage-ratio profile, while a large majority of unbiased subjects have a neutral attitude 
with respect to the composition of the balance sheet.27 In fact, the wealth perception bias corresponds to a markedly larger probability to borrow under the lower leverageratio profile. This confirms that biased subjects feel wealthier for lower values of the leverage ratio and this entails a greater likelihood to take on debt for consumption. Finally, conditionally on being biased, the higher the bias degree, the higher the probability of choosing to borrow under the lower leverage-ratio profile.

\section{CONCLUSION}

Our laboratory experiment highlights the presence of a wealth perception bias, characterized by a tendency to perceive a given net worth as greater than its actual value, even if frictions and uncertainty are absent. Specifically, a lower leverage ratio amplifies the magnitude of this wealth misperception. There is a cognitive underpinning to this result: subjects with wealth misperception think in proportions and direct their attention towards the leverage ratio, an improper measure of the balance sheet composition in the context of our experiment.

We conclude that the behavior of biased subjects is explained by their lower level of cognitive sophistication, relative to unbiased subjects. Indeed, they are System 1 thinkers, with a tendency to form perceptual values by means of proportions. Moreover, the presence and the magnitude of wealth misperception has a non-negligible impact on subjects' consumption and borrowing decisions. Relative to unbiased subjects, those with the wealth perception bias are less debt averse and have a greater tendency to rely on borrowing as a means to finance consumption and react to a financial emergency. In addition, greater misperception correlates with an increase in consumption spending in response to unexpected and transitory positive income shocks, thus predicting lower consumption smoothing for biased subjects compared to unbiased individuals.

Our work has different implications for policy. The experimental results suggest that removing potential sources of frictions may not be sufficient to prevent the formation of biases that, through the erroneous perception of wealth, impact agents' spending and borrowing behavior. Similarly, we find that greater financial education or experience with basic financial instruments do not have any impact on wealth misperception and the corresponding consumption and debt decisions. Further research should investigate whether the correlation between low cognitive sophistication and the greater probability of being biased may be related to the presence of cognitive load that temporarily limits the attentional resources available at the time of decision-making.

\footnotetext{
${ }^{27}$ Moreover, consistent with the results from the first question, unbiased subjects generally oppose the idea of debt-financed spending.
} 


\section{References}

Abeler, J. and Marklein, F. (2017). Fungibility, Labels, and Consumption. Journal of the European Economic Association, 15(1):99-127.

Agarwal, S. (2007). The impact of Homeowners' housing wealth misestimation on consumption and saving decisions. Real Estate Economics, 35(2):135-154.

Agarwal, S. and Mazumder, B. (2013). Cognitive abilities and household financial decision making. American Economic Journal: Applied Economics, 5(1):193-207.

Allred, S., Duffy, S., and Smith, J. (2016). Cognitive load and strategic sophistication. Journal of Economic Behavior and Organization, 125:162-178.

Attanasio, O. P., Guiso, L., and Jappelli, T. (2002). The demand for money, financial innovation, and the welfare cost of inflation: An analysis with household data. Journal of Political Economy, 110(2):317-351.

Barrett, L. F., Tugade, M. M., and Engle, R. W. (2004). Individual differences in working memory capacity and dual-process theories of the mind. Psychological Bulletin, 130(4):553573.

Ben-Shakhar, G. and Sheffer, L. (2001). The relationship between the ability to divide attention and standard measures of general cognitive abilities. Intelligence, 29(4):293-306.

Bertrand, M. and Morse, A. (2011). Information Disclosure, Cognitive Biases, and Payday Borrowing. Journal of Finance, 66(6):1865-1893.

Bialek, M. and Pennycook, G. (2018). The cognitive reflection test is robust to multiple exposures. Behavior Research Methods, 50(5):1953-1959.

Bosch-Rosa, C., Meissner, T., and Bosch-Domènech, A. (2018). Cognitive bubbles. Experimental Economics, pages 132-153.

Camarda, C. G., Eilers, P. H. C., and Gampe, J. (2017). Modelling general patterns of digit preference. Journal of the Royal Statistical Society: Series C (Applied Statistics), 66(5):893918.

Carlin, B., Olafsson, A., and Pagel, M. (2019). FinTech and Consumer Well-Being in the Information Age. Mimeo. 
Chen, D. L., Schonger, M., and Wickens, C. (2016). oTree-An open-source platform for laboratory, online, and field experiments. Journal of Behavioral and Experimental Finance, 9:88-97.

Chien, Y. I. and Devaney, S. A. (2001). The effects of credit attitude and socioeconomic factors on credit card and installment debt. Journal of Consumer Affairs, 35(1):162-179.

Corradin, S., Fillat, J., and Vergara-Alert, C. (2017). Portfolio choice with house value misperception. Federal Reserve of Boston Working Papers, 17-16.

de Langhe, B. and Puntoni, S. (2015). Bang for the Buck: Gain-Loss Ratio as a Driver of Judgment and Choice. Management Science, 61(5):1137-1163.

Dohmen, T., Falk, A., Huffman, D., Sunde, U., Schupp, J., and Wagner, G. G. (2011). Individual risk attitudes: Measurement, determinants, and behavioral consequences. Journal of the European Economic Association, 9(3):522-550.

Dukas, R. (2004). Causes and consequences of limited attention. In Brain, Behavior and Evolution, volume 63, pages 197-210.

Frederick, S. (2005). Cognitive Reflection and Decision Making. Journal of Economic Perspectives, 19(4):25-42.

Friedrich, J., Lucas, G., and Hodell, E. (2005). Proportional reasoning, framing effects, and affirmative action: Is six of one really half a dozen of another in university admissions? Organizational Behavior and Human Decision Processes, 98(2):195-215.

Fuster, A., Kaplan, G., and Zafar, B. (2020). What Would You Do with \$500? Spending Responses to Gains, Losses, News and Loans. The Review of Economic Studies.

Gabaix, X. (2014). A sparsity-based model of bounded rationality. Quarterly Journal of Economics, 129(4):1661-1710.

Gillard, E., Van Dooren, W., Schaeken, W., and Verschaffel, L. (2009). Proportional Reasoning as a Heuristic-Based Process: Time Constraint and Dual Task Considerations. Experimental Psychology, 56(2):92-99.

Hastings, W. K. (1970). Monte carlo sampling methods using Markov chains and their applications. Biometrika, 57(1):97-109. 
Holt, C. A. and Laury, S. K. (2002). Risk aversion and incentive effects. American Economic Review, 92(5):1644-1655.

Kahneman, D. (1973). Attention and effort. Prentice-Hall, Englewood Cliffs, NJ.

Kahneman, D. (2003a). A perspective on judgment and choice: mapping bounded rationality. American Psychologist, 58(9), 697-720. American Psychologist, 58(9):687-720.

Kahneman, D. (2003b). Maps of bounded rationality: Psychology for behavioral economics. American Economic Review, 93(5):1449-1475.

Khaw, M. W., Li, Z., and Woodford, M. (2019). Cognitive Imprecision and Small-Stakes Risk Aversion. NBER Working Paper, 24978.

Kihlstrom, J. F. (1987). The cognitive unconscious. Science, 237(4821):1445-1452.

Levi, Y. (2015). Information Architecture and Intertemporal Choice: A Randomized Field Experiment in the United States. Mimeo.

Lusardi, A. and Tufano, P. (2015). Debt literacy, financial experiences, and overindebtedness. Journal of Pension Economics and Finance, 14(4):332-368.

Metropolis, N., Rosenbluth, A. W., Rosenbluth, M. N., Teller, A. H., and Teller, E. (1953). Equation of state calculations by fast computing machines. The Journal of Chemical Physics, 21(6):1087-1092.

Modigliani, F. and Miller, M. H. (1958). The Cost of Capital, Corporation Finance and the Theory of Investment. American Economic Review, 68(3):261 - 297.

Morewedge, C. K., Holtzman, L., and Epley, N. (2007). Unfixed Resources: Perceived Costs, Consumption, and the Accessible Account Effect. Journal of Consumer Research, 34(4):459467.

Moritz, B., Siemsen, E., and Kremer, M. (2014). Judgmental forecasting: Cognitive reflection and decision speed. Production and Operations Management, 23(7):1146-1160.

Mullainathan, S. and Shafir, E. (2014). Scarcity: The True Cost of Not Having Enough. Penguin Books.

Parker, J. A. (2017). Why don't households smooth consumption? Evidence from a $\$ 25$ million experiment. American Economic Journal: Macroeconomics, 9(4):153-183. 
Parker, J. A. and Souleles, N. S. (2017). Reported Preference vs. Revealed Preference: Evidence from the Propensity to Spend Tax Rebates. NBER Working Paper, 23290.

Parker, J. A., Souleles, N. S., Johnson, D. S., and McClelland, R. (2013). Consumer spending and the economic stimulus payments of 2008. American Economic Review, 103(6):25302553.

Shiller (2015). Irrational Exuberance: revised and expanded. Princeton University Press.

Simon, H. A. (1978). Rationality as Process and as Product of Thought. American Economic Review, 68(2):1-16.

Sims, C. A. (2003). Implications of rational inattention. Journal of Monetary Economics, 50(3):665-690.

Stango, V. and Zinman, J. (2009). Exponential Growth Bias and Household Finance. The Journal of Finance, 64(6):2807-2849.

Stango, V. and Zinman, J. (2014). Limited and varying consumer attention: Evidence from shocks to the salience of bank overdraft fees. Review of Financial Studies, 27(4):990-1030.

Stanovich, K. E. and West, R. F. (2003). Individual differences in reasoning: Implications for the rationality debate? Behavioral and Brain Sciences, 23:645-726.

Sussman, A. B. and Shafir, E. (2012). On assets and debt in the psychology of perceived wealth. Psychological science, 23(1):101-8.

Thaler, R. H. (1990). Anomalies: Saving, Fungibility, and Mental Accounts. Journal of Economic Perspectives, 4(1):193-205.

Toplak, M. E., West, R. F., and Stanovich, K. E. (2011). The Cognitive Reflection Test as a predictor of performance on heuristics-and-biases tasks. Memory and Cognition, 39(7):12751289.

van Rooij, M., Lusardi, A., and Alessie, R. (2011). Financial literacy and stock market participation. Journal of Financial Economics, 101(2):449-472.

Weber, E. U. (2004). Perception Matters: Psychophysics for Economists. In Carrillo, J. and Brocas, I., editors, Psychology and Economics, pages 165-176. 


\section{A EXPERIMENT INSTRUCTIONS}

The experiment was carried out in Italian. Instructions were displayed on the computer screen before the beginning of each task. The following pages report an English translation.

\section{WELCOME}

Please take your time to read the instructions very carefully: there is no benefit to moving fast through the experiment. Today's experiment is made of five different parts: Task 1, Task 2, Task 3, Task 4 and Task 5. In each part, you will have to answer some questions. If you pay attention and complete your tasks, you may earn a considerable amount of money in each part. At the end of the experiment you will be paid a participation fee of $5 €$ plus the amount won in each of the three parts. In the next page you will be presented with the instructions of Task 1.

After completing Task 1, you will access the other tasks and the corresponding instructions. During the experiment you are not allowed to talk to the other participants, use cell phones or start any other programs on the computer. The neglect of these rules will lead to the immediate exclusion from the experiment and all payments. If you have any questions, please raise your hand.

Please proceed to the next page when you are ready to start.

\section{TASK 1 - Introduction}

The financial profile of an individual is generally represented by his assets, liabilities and net worth. Assets refers to the money that represents a person's wealth. Liabilities refers to debt, that is the money a person has to give back. Net worth refers to the difference between assets and liabilities and it may be either positive (if assets are greater than liabilities) or negative (in the opposite case). For example, the following table represents the financial profile of Mr. Rossi:

\begin{tabular}{cc}
\multicolumn{2}{c}{ Sig. Rossi } \\
\hline Attività & $8.000 €$ \\
Passività & $2.000 €$ \\
\hline Saldo & $6.000 €$
\end{tabular}

Figure 5. ExAmple of A FinANCIAL PRofile

In the example (in Fig. 5), Mr. Rossi has $8000 €$ worth of assets and $2000 €$ worth of liabilities. His net worth is therefore equal to $6000 €$.

TASK 1 - Your task 
In the next pages you will be shown 7 pairs of financial profiles, described by assets, liabilities and net worth, in line with what mentioned above.

For each pair, you will have to choose the profile that you consider financially superior. Be careful: once you confirm your choice, you will not be able to modify it. In making your decisions, keep in mind the following information:

1. All values of assets and liabilities shown are certain, that is they do not change over time;

2. The two profiles in each pair correspond to people who earn the same monthly income;

3. Both individuals in each pair can obtain new loans under the same conditions(i.e. at the same interest rate), if necessary;

4. All assets and liabilities are non-interest bearing: both individuals in each pair do not pay any interest on their debt and do not receive any interest on their assets.

Please proceed to the next page when you are ready to start.

Fig. 6 reports pairs shown to participants (sorted randomly for each participant) in task 1:

\section{TASK 2 - Introduction}

This task maintains the information provided in the previous task. So, the meaning of assets, liabilities and net worth remains the same as before. For the sake of clarity, we summarize them again here: Assets refers to the money that represents a person's wealth. Liabilities refers to debt, that is the money a person has to give back. Net worth refers to the difference between assets and liabilities and it may be either positive (if assets are greater than liabilities) or negative (in the opposite case).

\section{TASK 2 - Your task}

In this task you will be shown 10 financial profiles given by assets, liabilities and net worth. Next to each profile, you will find a pointer on a bar, like this one (Fig. 7):

Your task consists in evaluating the financial superiority of each profile by assigning a grade between 1 and 10. To do so, move the pointer along the bar corresponding to each profile.

In the range of grades, 1 indicates that your evaluation is extremely negative (you think the profile is not at all financially solid); 10 indicates that your evaluation is extremely positive (you think the profile is very solid from a financial perspective).

If you consider any profiles as financially equivalent, please assign them any same grade. In making your decisions, keep in mind the following information: 


\begin{tabular}{|c|c|c|c|}
\hline \multicolumn{2}{|c|}{ Mr. A } & \multicolumn{2}{|c|}{ Mr. B } \\
\hline Attività & $1.200 €$ & Attività & $15.000 €$ \\
\hline Passività & $200 €$ & Passività & $14.000 €$ \\
\hline Saldo & $1.000 €$ & Saldo & $1.000 €$ \\
\hline \multicolumn{2}{|c|}{ Mr. A } & \multicolumn{2}{|c|}{ Mr. B } \\
\hline Attività & $44.200 €$ & Attività & $12.800 €$ \\
\hline Passività & $32.000 €$ & Passività & $600 €$ \\
\hline Saldo & $12.200 €$ & Saldo & $12.200 €$ \\
\hline \multicolumn{2}{|c|}{ Mr. A } & \multicolumn{2}{|c|}{ Mr. B } \\
\hline Attività & $50.000 €$ & Attività & $69.500 €$ \\
\hline Passività & $800 €$ & Passività & $20.300 €$ \\
\hline Saldo & $49.200 €$ & Saldo & $49.200 €$ \\
\hline \multicolumn{2}{|c|}{ Mr. A } & \multicolumn{2}{|c|}{ Mr. B } \\
\hline Attività & $32.000 €$ & Attività & $74.800 €$ \\
\hline Passività & $7.350 €$ & Passività & $50.150 €$ \\
\hline Saldo & $24.650 €$ & Saldo & $24.650 €$ \\
\hline \multicolumn{2}{|c|}{ Mr. A } & \multicolumn{2}{|c|}{ Mr. B } \\
\hline Attività & $135.000 €$ & Attività & $613.000 €$ \\
\hline Passività & $7.000 €$ & Passività & $485.000 €$ \\
\hline Saldo & $128.000 €$ & Saldo & $128.000 €$ \\
\hline \multicolumn{2}{|c|}{ Mr A } & \multicolumn{2}{|c|}{ Mr B } \\
\hline Attività & $1.300 €$ & Attività & $17.000 €$ \\
\hline Passività & & Passività & \\
\hline Saldo & $1.000 €$ & Saldo & $1.000 €$ \\
\hline \multicolumn{2}{|c|}{ Mr A } & \multicolumn{2}{|c|}{ Mr B } \\
\hline Attività & & Attività & \\
\hline Passività & $33.000 €$ & Passività & $12.500 €$ \\
\hline Saldo & $11.200 €$ & Saldo & $11.200 €$ \\
\hline
\end{tabular}

Figure 6. PAirs ShOWn to PARTICIPANTS IN TASK 1

1. All values of assets and liabilities shown are certain, that is they do not change over time;

2. All profiles correspond to people who earn the same monthly income;

3. All these people can obtain new loans under the same conditions (i.e. any same amount; the same interest rate), if necessary;

4. All assets and liabilities are non-interest bearing: all individuals do not pay any interest on their debt and do not receive any interest on their assets.

Please proceed to the next page when you are ready to start.

\section{TASK 3}

Task 3 consists of some questions of different difficulty. Try to answer as many of them as possible. You have 2 minutes and 30 seconds of time for each question. 


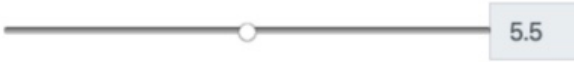

Figure 7. GRADING BAR

Think carefully about the answer you choose: For each correct answer in this task we will pay you $2 €$.

Please proceed to the next page when you are ready to start.

QUESTIONS shown to participants (one per page, sequentially):

- A bat and a ball cost $1.10 €$. The bat costs $1 €$ more than the ball. How much does the ball cost?

- It takes 5 machines 5 minutes to make 5 widgets. How long would it take 100 machines to make 100 widgets?

- In a lake, there is a patch of lily pads. Every day, the patch doubles in size. If it takes 48 days for the patch to cover the entire lake, how long would it take for the patch to cover half of the lake?

\section{TASK 4}

This task is composed of a sequence of 10 decisions. For each decision, you have to choose between Option A and Option B, which are shown in the table (Fig. 8) below (the table will be shown also in the next pages, so you don't have to learn it by heart).

After making all the 10 decisions, your computer will choose one of them randomly. Each of the 10 decisions has an equal probability of being chosen. Based on the selected decision, your computer will then determine the amount of your pay. To this purpose, your computer will throw a 10 -sided dice and play the associated lottery.

For example, imagine your computer selects decision number 1. Your computer will then throw the 10-sided dice: if you have chosen option A, you will win $2 €$ if the dice shows the side " 1 ", or $1.6 €$ if the dice shows one of the other 9 sides; if instead you have chosen option B, you will win $3.85 €$ if the dice shows the side " 1 ", or $0.10 €$ if the dice shows one of the other 9 sides.

Hence, even if you make 10 decisions, only one of them will determine your payment in this task. Clearly, as already pointed out, each decision has an equal probability of being chosen for your payment but you have no possibility to know in advance which of the decisions is going to be selected. 


\begin{tabular}{|c|c|c|}
\hline Decisione & Opzione A & Opzione B \\
\hline 1 & $\begin{array}{c}\text { Vincere } 2,00 € \text { con probabilità } 1 \text { su } 10 \\
\text { OPPURE } \\
\text { Vincere } 1,60 € \text { con probabilità } 9 \text { su } 10\end{array}$ & $\begin{array}{c}\text { Vincere } 3,85 € \text { con probabilità } 1 \text { su } 10 \\
\text { OPPURE } \\
\text { Vincere } 0,10 € \text { con probabilità } 9 \text { su } 10\end{array}$ \\
\hline 2 & $\begin{array}{l}\text { Vincere } 2,00 € \text { con probabilità } 2 \text { su } 10 \\
\text { OPPURE } \\
\text { Vincere } 1,60 € \text { con probabilità } 8 \text { su } 10\end{array}$ & $\begin{array}{l}\text { Vincere } 3,85 € \text { con probabilità } 2 \text { su } 10 \\
\text { OPPURE } \\
\text { Vincere } 0,10 € \text { con probabilità } 8 \text { su } 10\end{array}$ \\
\hline 3 & $\begin{array}{c}\text { Vincere } 2,00 € \text { con probabilità } 3 \text { su } 10 \\
\text { OPPURE } \\
\text { Vincere } 1,60 € \text { con probabilità } 7 \text { su } 10\end{array}$ & $\begin{array}{c}\text { Vincere } 3,85 € \text { con probabilità } 3 \text { su } 10 \\
\text { OPPURE } \\
\text { Vincere } 0,10 € \text { con probabilità } 7 \text { su } 10\end{array}$ \\
\hline 4 & $\begin{array}{l}\text { Vincere } 2,00 € \text { con probabilità } 4 \text { su } 10 \\
\text { OPPURE } \\
\text { Vincere } 1,60 € \text { con probabilità } 6 \text { su } 10\end{array}$ & $\begin{array}{l}\text { Vincere } 3,85 € \text { con probabilità } 4 \text { su } 10 \\
\text { OPPURE } \\
\text { Vincere } 0,10 € \text { con probabilità } 6 \text { su } 10\end{array}$ \\
\hline 5 & $\begin{array}{c}\text { Vincere } 2,00 € \text { con probabilità } 5 \text { su } 10 \\
\text { OPPURE } \\
\text { Vincere } 1,60 € \text { con probabilità } 5 \text { su } 10\end{array}$ & $\begin{array}{c}\text { Vincere } 3,85 € \text { con probabilità } 5 \text { su } 10 \\
\text { OPPURE } \\
\text { Vincere } 0,10 € \text { con probabilità } 5 \text { su } 10\end{array}$ \\
\hline 6 & $\begin{array}{l}\text { Vincere } 2,00 € \text { con probabilità } 6 \text { su } 10 \\
\text { OPPURE } \\
\text { Vincere } 1,60 € \text { con probabilità } 4 \text { su } 10\end{array}$ & $\begin{array}{l}\text { Vincere } 3,85 € \text { con probabilità } 6 \text { su } 10 \\
\text { OPPURE } \\
\text { Vincere } 0,10 € \text { con probabilità } 4 \text { su } 10\end{array}$ \\
\hline 7 & $\begin{array}{l}\text { Vincere } 2,00 € \text { con probabilità } 7 \text { su } 10 \\
\text { OPPURE } \\
\text { Vincere } 1,60 € \text { con probabilità } 3 \text { su } 10\end{array}$ & $\begin{array}{c}\text { Vincere } 3,85 € \text { con probabilità } 7 \text { su } 10 \\
\text { OPPURE } \\
\text { Vincere } 0,10 € \text { con probabilità } 3 \text { su } 10\end{array}$ \\
\hline 8 & $\begin{array}{l}\text { Vincere } 2,00 € \text { con probabilità } 8 \text { su } 10 \\
\text { OPPURE } \\
\text { Vincere } 1,60 € \text { con probabilità } 2 \text { su } 10\end{array}$ & $\begin{array}{l}\text { Vincere } 3,85 € \text { con probabilità } 8 \text { su } 10 \\
\text { OPPURE } \\
\text { Vincere } 0,10 € \text { con probabilità } 2 \text { su } 10\end{array}$ \\
\hline 9 & $\begin{array}{l}\text { Vincere } 2,00 € \text { con probabilità } 9 \text { su } 10 \\
\text { OPPURE } \\
\text { Vincere } 1,60 € \text { con probabilità } 1 \text { su } 10\end{array}$ & $\begin{array}{l}\text { Vincere } 3,85 € \text { con probabilità } 9 \text { su } 10 \\
\text { OPPURE } \\
\text { Vincere } 0,10 € \text { con probabilità } 1 \text { su } 10\end{array}$ \\
\hline 10 & $\begin{array}{l}\text { Vincere } 2,00 € \text { con probabilità } 10 \text { su } 10 \\
\text { OPPURE } \\
\text { Vincere } 1,60 € \text { con probabilità } 0 \text { su } 10\end{array}$ & $\begin{array}{l}\text { Vincere } 3,85 € \text { con probabilità } 10 \text { su } 10 \\
\text { OPPURE } \\
\text { Vincere } 0,10 € \text { con probabilità } 0 \text { su } 10\end{array}$ \\
\hline
\end{tabular}

Figure 8. Sequence of DeCisions

Please proceed to the next page when you are ready.

\section{TASK 5}

The last task consists of a short survey. Please take the necessary amount of time to answer accurately.

How old are you?

What is your gender? 
A: female, male

How many people live in your family?

A: $1,2,3,4,5+$

What is your parents' education level?

A:None of my parents holds a degree; Only one of my parents holds a degree; Both of my parents hold a degree

Do you have any financial education?

A: Yes, No

Have you ever participated in experiments like this one before?

A: Yes, No

Do you have at least one credit or debit card?

A: Yes; No

In general, do you prefer to spend money and enjoy it today or save for the future?

A: Spend and enjoy it today; Save for the future

In general, do you think it is a good idea or a bad idea for people to buy things by borrowing?

A: Good idea; Good in some ways, bad in others; Bad idea

If tomorrow you experienced a financial emergency that left you unable to pay all of your bills, how would you deal with it?

A: Borrow money; Spend out of savings; Postpone payments; Cut back; Other

Imagine that your TV is getting old and you want to change it with a new flat screen HD smart TV. However, since you don't have the money to purchase it outright, you would need to borrow $450 €$ in order to buy it. In which case would you be more likely to borrow to buy the new TV?

A: Mr. A; Mr. B; I would borrow in either case; I would not borrow in either case. 


\begin{tabular}{ccccc}
\multicolumn{2}{c}{ Mr. A } & & \multicolumn{2}{c}{ Mr. B } \\
\cline { 1 - 2 } \cline { 4 - 5 } Attività & $3.500 €$ & & Attività & $19.000 €$ \\
Passività & $0 €$ & & Passività & $15.500 €$ \\
\cline { 1 - 2 } \cline { 5 - 6 } Saldo & $3.500 €$ & & Saldo & $3.500 €$
\end{tabular}

Figure 9. Hypothetical PROFILES

Consider a hypothetical situation in which you unexpectedly receive a one-time payment of $500 €$. What would you do over the next month?

A: I would spend more than if I hadn't received the 500€; I would spend the same as if I had not received the $500 €$; I would spend less than if I ha not received the $500 €$.

CONDITIONAL: You indicated that you would increase your spending over the next month following the receipt of the $500 €$ payment. How much more would you spend than if you hadn't received the $500 €$ ?

Consider a hypothetical situation in which you unexpectedly receive a one-time payment of $5000 €$ Euros. What would you do over the next month?

A: I would spend more than if I hadn't received the 5000€; I would spend the same as if I had not received the $5000 €$; I would spend less than if I had not received the $5000 €$.

CONDITIONAL: You indicated that you would increase your spending over the next month following the receipt of the $5000 €$ payment. How much more would you spend than if you hadn't received the $5000 €$ ?

Consider again a hypothetical situation in which you unexpectedly receive a one-time payment of $500 €$ today. In which case would you be more likely to increase your expenses?

\begin{tabular}{ccccc}
\multicolumn{2}{c}{ Mr. A } & & \multicolumn{2}{c}{ Mr. B } \\
\cline { 1 - 1 } \cline { 4 - 5 } Attività & $3.500 €$ & & Attività & $19.000 €$ \\
Passività & $0 €$ & & Passività & $15.500 €$ \\
\cline { 5 - 6 } \cline { 5 - 6 } Saldo & $3.500 €$ & & Saldo & $3.500 €$
\end{tabular}

Figure 10. HypotheticAl PROFILES

A: Mr. A; Mr. B; I would increase my expenses in either case; I would not increase my expenses in either case 


\section{B ATTITUDES TOWARDS CONSUMPTION AND DEBT}

Table 9 show the distribution of biased and unbiased subjects for the consumption questions in the final survey. Analogously, Table 10 shows the distribution of subjects for the debt questions in the survey.

Table 9. Attitudes toward Consumption

\begin{tabular}{|c|c|c|}
\hline & Biased (\%) & Unbiased (\%) \\
\hline \multicolumn{3}{|c|}{ Panel $A$ - Saving type } \\
\hline Patient & 37.31 & 81.82 \\
\hline Impatient & 62.69 & 18.18 \\
\hline \multicolumn{3}{|c|}{ Panel $B$ - Spending response - $500 €$} \\
\hline Less & 4.48 & 9.09 \\
\hline Same & 47.76 & 72.73 \\
\hline More & 47.76 & 18.18 \\
\hline \multicolumn{3}{|c|}{ Panel $C$ - Spending response - $5000 €$} \\
\hline Less & 4.48 & 9.09 \\
\hline Same & 37.31 & 45.45 \\
\hline More & 58.21 & 45.45 \\
\hline \multicolumn{3}{|c|}{ Panel D - Profile type } \\
\hline Low-Ratio Profile & 74.63 & 9.09 \\
\hline High-Ratio Profile & 7.46 & 9.09 \\
\hline Neutral & 17.91 & 81.82 \\
\hline \multicolumn{3}{|c|}{$\begin{array}{l}\text { Notes. Panel A - Patient: "Save for the future"; Impatient: "Spend now". Panel B and C-Less: "I would spend } \\
\text { less than if I had not received the } 500 €(5000 €) \text { )"; Same: "I would spend the same as if I had not received the } \\
500 €(5000 €) \text { "; More: "I would spend more than if I had not received the } 500 €(5000 €) \text { ". Panel D-Low-ratio } \\
\text { profile: percentage of subjects that would increase spending out of an unexpected gain under the lower leverage } \\
\text { ratio profile; High-ratio profile: percentage of subjects that would increase spending out of an unexpected gain } \\
\text { under the higher leverage ratio profile; Neutral: percentage of subjects that would increase spending out of an } \\
\text { unexpected gain under any profile (or would not increase spending at all). }\end{array}$} \\
\hline
\end{tabular}


Table 10. Attitudes toward Debt

\begin{tabular}{lcc}
\hline \hline & Biased (\%) & Unbiased (\%) \\
\hline Panel A - Debt attitude & & \\
Averse & 11.94 & 36.36 \\
Seeker & 37.31 & 9.09 \\
Neutral & 50.75 & 54.55 \\
\hline
\end{tabular}

Panel B - Financial emergency response

\begin{tabular}{lcc} 
Borrow & 44.78 & 9.09 \\
Use savings & 13.43 & 36.36 \\
Postpone & 5.97 & 9.09 \\
Cut & 32.84 & 36.36 \\
Other & 2.99 & 9.09 \\
\hline Panel C- Borrowing for consumption & & \\
& & \\
Low-Ratio Profile & 77.61 & 9.09 \\
High-Ratio Profile & 4.48 & 0 \\
Neutral & 17.91 & 90.91
\end{tabular}

Notes. Panel A - Averse: "spending by borrowing is a bad idea"; Seeker: "spending by borrowing is a good idea"; Neutral: "spending by borrowing is good in some ways, bad in others". Panel B - Borrow: "Borrow money"; Use savings: "Spend out of savings"; Postpone: "Postpone payments"; Cut: "Cut back"; Other: "Other". Panel CLow-ratio profile: percentage of subjects that would take the loan under the lower leverage ratio profile; High-ratio profile: percentage of subjects that would take the loan under the higher leverage ratio profile; Neutral: percentage of subjects that would take the loan under any profile (or would not take the loan at all). 


\section{INTERNET APPENDIX}

\section{C1. A model of behavioral inattention}

In this Appenidx we introduce a simple two-period optimal consumption model to rationalize our experimental results. The model features two types of agents: a standard rational agent, representing unbiased subjects in our experiment, who will be our benchmark; a behavioral agent à la Gabaix (2014), who has a wrong perception of her wealth due to low cognitive sophistication and inattention. In particular, our behaviorally inattentive agent has three distinctive characteristics.

First, in line with the sparse-max operator described in Gabaix (2014), the optimization problem for this agent consists of two steps. In the first step, the agent builds a perceived value of her total net wealth by choosing the optimal amount of attention to allocate to the problem; then, she chooses the optimal consumption level, conditional on her perception of wealth. Consumption allocation is therefore the outcome of a process endowed with procedural rationality but no substantive rationality (Simon, 1978), as the agent's consumption decision is not determined exclusively by the characteristics of the environment but, rather, by her perception of it.

Secondly, the perceived value of net wealth depends on two components: the true value of net wealth and a noisy representation of it, whose level is positively correlated with the magnitude of the leverage ratio - in line with the wealth perception bias found in the experiment. Eventually, the level of cognitive sophistication of the agent (i.e. the extent to which her System 2 prevails over her System 1) determines the amount of optimal attention. In turn, this establishes whether perceived wealth is ultimately closer to the true level or to the noisy representation of it.

Finally, in line with our experimental results, the biased agent is characterized by a predominance of System 1 over System 2, due to a low level of cognitive sophistication. Hence, she does not allocate full attention to the true value of her wealth. This results in a perceived level of wealth that is different from the actual value.

Rational (unbiased) agent. Let us start by describing the behavior of the rational agent. We assume a well-behaved utility function, such that the rational agent chooses the intertemporal consumption allocation optimally by maximizing her utility subject to the budget constraint in 
period one and in period two. Hence, she solves the following problem:

$$
\begin{array}{ll} 
& \max U\left(c_{1}, c_{2}\right)=U\left(c_{1}\right)+\beta U\left(c_{2}\right) \\
\text { s.t. } & c_{1}=y_{1}+b \text { and } c_{2}+(1+r) b=y_{2}
\end{array}
$$

where $c_{t}(t=1,2)$ identifies consumption in each period, while $y_{t}(t=1,2)$ represents the endowment in each period. In particular, $y_{1}$ is assumed to be determined by two components: the actual income received in period $1\left(\hat{y}_{1}\right)$ and a stock of net wealth $(N W)$ composed of assets (A) and debt $(D)$, so that $y_{1}=\hat{y}_{1}+N W$, where $N W=A-D$. Finally, $r$ is the real interest rate and $b$ is either savings, if positive, or debt, if negative. Hence, the agent total (net) wealth is $w=y_{1}+\frac{y_{2}}{1+r}$, while the inter-temporal budget constraint is:

$$
c_{2}=(1+r)\left(y_{1}-c_{1}\right)+y_{2}
$$

The optimization problem yields the standard Euler Equation:

$$
\frac{U_{c_{1}}^{\prime}}{U_{c_{2}}^{\prime}}=\beta(1+r)
$$

By combining Equations 3 and 4, we find the optimal consumption levels for the rational agent, which are a function of the interest rate and total net wealth of the agent. In the following we will refer to optimal consumption allocation for the rational agent in period one and period two with $c_{1}^{*}\left(r, y_{1}, y_{2}\right)$ and $c_{2}^{*}\left(r, y_{1}, y_{2}\right)$ respectively.

Biased agent. We model the behavior of the biased agent after the behavioral inattention setup introduced by Gabaix (2014) with some slight departures. As in Gabaix, the agent faces the standard optimization problem, but she solves it in two steps according to the sparse-max operator (Gabaix, 2014): first, she decides the optimal amount of attention to allocate to the problem, so as to form a perceived value of wealth; second, the agent chooses the optimal consumption allocation of the two periods, conditional on her perception.28

The biased agent in our model is characterized by limited cognitive sophistication and the wealth perception bias found in the experiment. Hence, the agent does not pay full attention to the problem, so that her perceived wealth does not correspond to the actual wealth. The

\footnotetext{
${ }^{28} \mathrm{We}$ model behavioral inattention via sparse-maxity, rather than following the approach with an entropy penalty by Sims (2003), because "the sparse max allows for source-dependent inattention, and is more tractable" (Gabaix, 2014, p. 1696). In fact, Sims (2003) formulation dampens equally all dimensions, while in the sparse-max approach developed by Gabaix (2014), the level of attention is dimension specific, so that less important dimensions are dampened more.
} 
consumption allocation of the biased agent will differ from that of the rational one. In the following we provide the details.

Behavioral inattention. The biased agent's actual net wealth is the same as the rational agent, that is $w=y_{1}+\frac{y_{2}}{1+r}$. We assume that her perceived wealth is $w^{s}=y_{1}^{s}+\frac{y_{2}}{1+r^{s}}$, where the ${ }^{s}$ superscript represents perceived (or sparse) values. Hence, the agent's perceived wealth deviates from her actual wealth due to a sparse representation of the endowment of period 1 and the interest rate.29

Assumption 1. $y_{1}^{s}$ and $r^{s}$ are defined as the following convex combinations:

$$
\begin{aligned}
& y_{1}^{s}=m_{1} y_{1}+\left(1-m_{1}\right) y_{1}^{d} \\
& r^{s}=m_{2} r+\left(1-m_{2}\right) r^{d}
\end{aligned}
$$

Variables with the ${ }^{d}$ superscript are individual default values, which identify the guess that spontaneously comes to mind with no time to think (Gabaix, 2014), or under limited cognitive resources. In Bayesian terms, the default could also be interpreted as the prior generated by System 1, which, being fast and inattentive, produces an inaccurate guess. The variable $m_{i} \in$ $[0,1], \forall i=1,2$, is a measure of attention, such that $m_{i}=1$ implies full attention, while $m_{i}=0$ implies no attention. Any value $0<m_{i}<1$ implies an inaccurate perception of the true value of the corresponding variable. When $m_{i}$ increases, the agent relies less on the default and more on the true value, i.e. System 2 takes over System 1.

Assumption 2. As a microfoundation, we model the default values as the true values altered by a distortion factor:

$$
\begin{aligned}
y_{1}^{d} & =y_{1}-g_{y_{1}} \\
r^{d} & =r+g_{r}
\end{aligned}
$$

$g_{y_{1}}$ and $g_{r}$ represent the distortion in the priors generated by System 1. Specifically, we describe $g_{y_{1}}=\psi \frac{D}{A}$, with $\log \psi \sim N(0, \eta)$, where $\eta$ is a finite variance, and $g_{r}=\gamma \frac{D}{A}$, with $\gamma \sim U(0,1) .30$ Equations 7 and 8 imply $y_{1}^{d}>y_{1}$ and $r^{d}<r$, which entail $w^{s}>w$, for any

\footnotetext{
${ }^{29}$ Notice that one could obtain similar qualitative results by applying sparsity on $y_{2}$ or other combinations of the components of wealth. However, this choice leads to an analytically simpler solution without altering the conclusions.

${ }^{30}$ Khaw et al. (2019) propose that judgments and choices be based on noisy mental representation of the situation and this involves an average bias in the optimal rule for forming such judgments and making these choices. In fact,
} 
$m_{i}<1, \forall i=1,2$. In other words, we assume that (i) the inaccurate guess on the value of the endowment generated by System 1 exceeds its true value and (ii) the magnitude of the deviation of $y_{1}^{d}\left(r^{d}\right)$ from $y_{1}(r)$ depends on a distortion affected by the leverage ratio $(D / A)$. 11 This aligns the idea that the intensity of the distortion should be directly connected to the size and nature of the noise in perceptual judgments (Khaw et al., 2019), while also capturing the key mechanism behind the wealth perception bias, namely the tendency to rely on proportional thinking. Indeed, a lower leverage ratio impacts positively on the mental representation of wealth, thereby increasing its deviation from the true level of actual wealth.

Lemma 1. Under Assumption 1 and Assumption 2 we have:

$$
\begin{aligned}
& y_{1}^{s}=y_{1}-\left(1-m_{1}\right) g_{y_{1}}>y_{1} \\
& r^{s}=r+\left(1-m_{2}\right) g_{r}<r
\end{aligned}
$$

Hence, given the true value, the overall biased perception of wealth is determined by two factors:

- The noisy representation of the true values generated by System 1, which, in turn, depends on the magnitude of the leverage ratio. In line with the wealth perception bias found in the experiment, the agent makes use of proportional thinking and a lower leverage ratio increases the value of the fast and inaccurate guesses produced by the less sophisticated mental process of System 1.

- The optimal level of attention $m_{i}^{*}$, which may be interpreted as the outcome of the interaction between System 1 and System 2, as in dual process theory (Kahneman, 2003a,b). For a sophisticated agent, System 2 fully overtakes System 1 so that $m_{i}=1, \forall i=1,2$. The agent is therefore rational and fully attentive, thereby having an unbiased perception that corresponds to the true value of wealth. On the contrary, for an agent with poor cognitive sophistication, System 1 prevails and $m_{i}$ tends to zero. This agent is rational but inattentive, thus having a perceived value of wealth that relies on her default and diverges from the true level. The overall amount of the deviation therefore ranges between $\left[0, g_{y_{1}}\right]$ for $y_{1}$ and $\left[0, g_{r}\right]$ for $r$.

\footnotetext{
"if there were no random noise in the internal representations on which the judgments are based, there should (if the subject forms optimal Bayesian judgments) be no noise in perceptual judgments, and no bias either" (Khaw) et al., 2019, p.4). This is philosophically analogous to our set up, in which there exists a strong link between the default values - i.e. the noisy sensory data generated by System 1 - and the perceptual representation of wealth.

${ }^{31}$ In the paper we focus on the case in which $w^{s}>w$ because our experimental findings confirm that all biased subjects in our experiment have an average bias degree greater than 1 . In other words, they all show a level of perceived wealth (on average) that is higher than actual wealth.
} 
Following Gabaix (2014), we define the optimal level of attention $\left(m^{*}\right)$ as given by a function with two additive components: the utility loss from imperfect attention and the psychological cost for the lack of sparsity. ${ }_{2}^{2}$ Specifically:

$$
m^{*}=\underset{m \in[0,1]}{\arg \min } \frac{1}{2} \sum_{i=1}^{2}\left(1-m_{i}\right)^{2} \Delta_{i i}+k(\theta) \sum_{i=1}^{2} m_{i}^{\alpha}
$$

where, in our setting, $\Delta_{i i}:=-\sigma_{i}^{2} a_{x_{i}} U_{a a} a_{x_{i}}$ is the benefit that the consumer enjoys when her attention on dimension $i$ goes from zero to one. $U_{a a}$ is the second derivative of the utility function with respect to action $a$, while $a_{x i}:=\frac{\partial a}{\partial x_{i}}$ identifies the marginal effect of a change in variable $x_{i}$ on the action (that is $-U_{a a}^{-1} U_{a x_{i}}$ ), evaluated at the default values of the action and the variable $x_{i}$. 33 In our set-up $x_{i}=\left[y_{1}, r\right]$ and $a=c_{1}$. When unable to observe the variable $x_{i}$, the agent uses the expected magnitude as a proxy, thus setting $\sigma_{i}=\mathbf{E}\left[x_{i}^{2}\right]^{\frac{1}{2}}$ and, trivially, $\Delta_{i i}:=-\mathbf{E}\left[x_{i}^{2}\right] a_{x_{i}} U_{a a} a_{x_{i}}$. Finally, the function $k(\theta)$ is the penalty for the lack of sparsity, such that the term $k(\theta) m_{i}^{\alpha}$ represents the psychological cost of attention. We follow Gabaix (2014) and assume that $\alpha=1$, so as to have both sparsity and continuity in the attention function. However, since attention is cognitively costly (Kahneman, 1973) and entails the allocation of scarce cognitive resources, we depart from the setup introduced in Gabaix (2014) by assuming that $k$ depends on the level of cognitive sophistication of the agent $(\theta)$. In particular:

$$
k(\theta)= \begin{cases}0, & \forall \theta \geq \bar{\theta} \\ \in\left(0, k_{\text {max }}\right], k(\theta)^{\prime}<0 & \forall \theta<\bar{\theta}\end{cases}
$$

where $\bar{\theta}$ represents a threshold in the level of cognitive sophistication. Hence, the case $\theta \geq \bar{\theta}$ corresponds to the rational agent, who is endowed with a high level of cognitive capacity, so that the cost is zero, attention is full and perceived wealth equals its true value. Nonetheless, biased subjects in our experiment have a greater tendency to rely on System 1, thus employing limited cognitive resources and attention. Hence, the case $\theta<\bar{\theta}$ corresponds to the biased agent, who is characterized by a low level of cognitive sophistication that, in turn, entails a high cost of attention, low $m^{*}$ and a level of perceived wealth that exceeds the actual value. 34 We assume that for zero cognitive sophistication, $k(0)=k_{\max }$ in order to avoid an infinitely positive cost of attention for an extremely cognitively unsophisticated agent.

\footnotetext{
${ }^{32}$ The interested reader is left to refer to Gabaix (2014) for a detailed explanation for this particular functional form.

${ }^{33}$ The default action corresponds to the optimal action under default values of $x$.

${ }^{34}$ The specific functional form of $k(\theta)$ in the interval $\left(0, k_{\max }\right]$ for $\theta<\bar{\theta}$ is not relevant for the purpose of our analysis. For the sake of simplicity we assume it is a linear function.
} 
From Equation 11 we obtain the optimal level of attention on dimension $i$ as a function of the cognitive cost $k(\theta)$ and the benefit $\Delta_{i i}$ :

$$
m_{i}^{*}=\max \left(1-\frac{k(\theta)}{\Delta_{i i}}, 0\right)
$$

where, in our setting, $\Delta_{11}:=-\mathbf{E}\left[y_{1}^{2}\right] a_{y_{1}} U_{c_{1} c_{1}} a_{y_{1}}$ and $\Delta_{22}:=-\mathbf{E}\left[r^{2}\right] a_{r} U_{c_{1} c_{1}} a_{r}$.

Therefore, for a given level of $\theta<\bar{\theta}$, if the corresponding cost is greater or equal to the benefit - i.e. $k(\theta) \geq \Delta_{i i}$ - attention on dimension $i$ will be zero. In all cases in which $k(\theta)<$ $\Delta_{i i}$, the agent will always pay at least some attention to the variable $i$. When $k(\theta)=0$ (i.e. when $\theta \geq \bar{\theta}$ ), attention is maximum and equal to 1 , regardless of $\Delta_{i i}$, and the agent is unbiased. 35

Figure 11.a plots the cognitive cost and optimal attention on $i$ as a function of the level of cognitive sophistication, for a given value of $\Delta_{i i}$. For $\theta \geq \bar{\theta}$, the cost $k(\theta)$ is zero, optimal attention is $m_{i}^{*}=1$ and the agent is unbiased. When $\theta<\bar{\theta}$, the lower the level of cognitive sophistication, the higher the corresponding cost and the lower the optimal level of attention. When $\theta$ is such that $k(\theta)$ exceeds $\Delta_{i i}$, optimal attention is zero. Figure 11.b shows optimal attention on $i$ as a function of $\Delta_{i i}$, for a given level of cognitive sophistication. When $\Delta_{i i} \leq k(\theta)$ optimal attention is zero, otherwise $m_{i}^{*}$ increases, as the benefit exceeds the cost of attention.

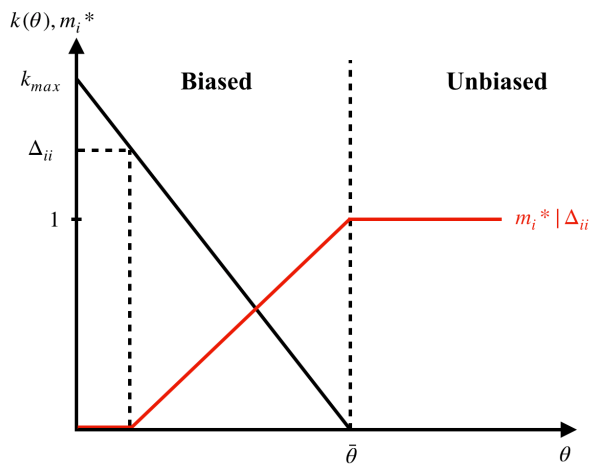

(a)

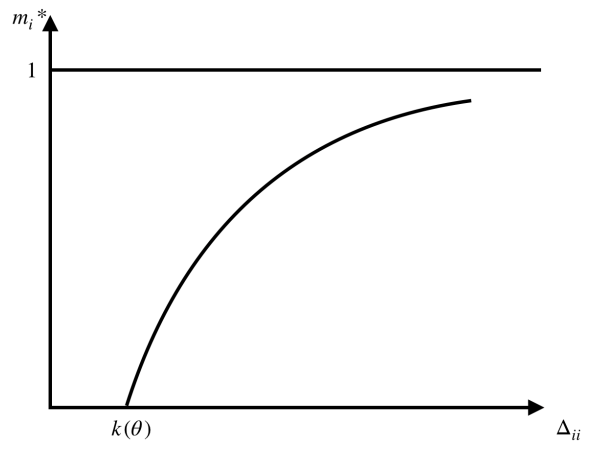

(b)

Figure 11. Cognitive Sophistication, Attention Cost and Optimal Attention

Figure 11.(a) plots attention cost $\left(k(\theta)\right.$, in black) and optimal attention ( $m_{i}^{*}$, in red) as a function of the level of cognitive sophistication $(\theta)$, for a given value of $\Delta_{i i}$. Figure 11.(b) shows optimal attention as a function of $\Delta_{i i}$, for a given value of $\theta$.

Summing up, our setup incorporates the main features of the standard sparse-max operator introduced in the behavioral inattention model by Gabaix (2014). In fact, attention on each vari-

\footnotetext{
${ }^{35}$ We assume that $\max \left(\Delta_{i i}\right) \leq k_{\max }$, so that the benefit of attention cannot exceed the maximum cost. This rules out the possibility that an agent with zero cognitive sophistication (and, therefore, maximum cost) has positive attention to the variable $i$.
} 
able increases (1) when the magnitude of the variable is higher; (2) when the variable impacts more on the action $a$; (3) if an imperfect action leads to a greater cost. However, differently from the original set-up, the cognitive cost $k$ is a function of the level of cognitive sophistication of the agent and default values depend on the level of the leverage ratio. This allows us to capture two key features. First, the level of cognitive sophistication correlates with wealth misperception. In the experiment, subjects with low scores in the Cognitive Reflection Test are more likely to be biased; in the model, when System 1 prevails over System 2, the agent is sparse and her level of cognitive sophistication is $\theta<\bar{\theta}$. Therefore, her attention is less than full and she relies more on the inaccurate prior generated by System 1.

Secondly, perceived wealth increases for lower values of the leverage ratio. The value of the fast and inaccurate prior of System 1 depends negatively on the level of the leverage ratio. Therefore, for a given level of cognitive sophistication and attention, a lower leverage ratio impacts positively on the perceived wealth of the biased agent.

Optimal action. After choosing attention optimally, the agent chooses the allocation of consumption conditional on her sparse representation of wealth. Hence, she solves the following problem:

$$
\begin{array}{ll} 
& \max U\left(c_{1}, c_{2}\right)=U\left(c_{1}\right)+\beta U\left(c_{2}\right) \\
\text { s.t. } & c_{2}=\left(1+r^{s}\right)\left(y_{1}^{s}-c_{1}\right)+y_{2} .
\end{array}
$$

The Euler equation for the sparse agent therefore is:

$$
\frac{U_{c_{1}}^{\prime}}{U_{c_{2}}^{\prime}}=\beta\left(1+r^{s}\right) .
$$

From the problem above we find the optimal allocation of consumption conditional on the biased perception of wealth, $c_{1}^{s}\left(r^{s}, y_{1}^{s}, y_{2}\right)$ and $c_{2}^{s}\left(r^{s}, y_{1}^{s}, y_{2}\right)$. However, this allocation lies on the perceived budget constraint, which is different from the actual one. Therefore, the optimal allocation is not feasible.

As pointed out by Gabaix (2014), the sparse agent is behavioral but smart enough to exhaust the true budget constraint, thereby adjusting the allocation of consumption accordingly. Since the agent is biased, the adjusted allocation $\left(c_{1}^{a}, c_{2}^{a}\right)$ has to depend on the perceived value of wealth (i.e. $r^{s}$ and $y_{1}^{s}$ ) while also being feasible, so that $c_{1}^{a}+\frac{c_{2}^{a}}{1+r}=y_{1}+\frac{y_{2}}{1+r}$. Therefore, we define an 
as-if intertemporal budget constraint as follows:

$$
c_{2}^{a}=\left(1+r^{s}\right)\left(y_{1}^{s}-c_{1}^{a}\right)+y_{2}^{\prime}
$$

Following Gabaix, the adjustment occurs by finding the value of $y_{2}^{\prime}$ that guarantees that the adjusted allocation is feasible, i.e. it is along the true budget constraint. Hence, the following condition has to be satisfied:

$$
c_{1}^{a}\left(r^{s}, y_{1}^{s}, y_{2}^{\prime}\right)+\frac{c_{2}^{a}\left(r^{s}, y_{1}^{s}, y_{2}^{\prime}\right)}{1+r}=y_{1}+\frac{y_{2}}{1+r}
$$

Therefore, the biased agent solves the following problem:

$$
\text { find } \quad y_{2}^{\prime} \quad \text { s.t. } \quad C^{a}\left(r^{s}, y_{1}^{s}, y_{2}^{\prime}\right)=w
$$

where $C^{a}\left(r^{s}, y_{1}^{s}, y_{2}^{\prime}\right)$ represents total adjusted consumption, that is the optimal allocation that is also feasible.

Rational vs. adjusted (sparse) allocation. We now identify the conditions under which the model replicates our experimental results. We know that biased subjects are more likely to borrow for consumption, relative to unbiased subjects. We also know that the presence of the wealth perception bias corresponds to a larger probability of being a spender, rather than a saver, and a greater tendency to increase spending out of unexpected gains.

Proposition 1 A necessary condition for the biased agent to be a borrower in period 1, i.e. $c_{1}^{a}>y_{1}$, and have positive consumption in period 2 , i.e. $c_{2}^{a}>0$, is:

$$
y_{2} \frac{1+r^{s}}{1+r}-\left(y_{1}^{s}-y_{1}\right)\left(1+r^{s}\right)<y_{2}^{\prime}<y_{2}-\left(y_{1}^{s}-y_{1}\right)\left(1+r^{s}\right) .
$$

Hence, for any value of $y_{2}^{\prime}$ that meets condition 19 , in the first period the biased agent consumes more than the period 1 endowment, thereby being a borrower. Condition 19 also allows for non-negative consumption in the second period (see the Appendix for the proof).

We now identify the condition under which the adjusted consumption of the biased agent in period 1 is larger than the consumption of the rational agent in the same period. To this purpose, we assume a Constant Relative Risk Aversion (CRRA) utility function. 3

PROPOSITION 2 Under the assumption of constant relative risk aversion, and Lemma $1, \forall y_{2}^{\prime}$

\footnotetext{
${ }^{36}$ It is indeed necessary to assume a functional form for the utility function in order to compare the behavior of the two agents. See the Appendix for a detailed discussion on this.
} 
satisfying $17, c_{1}^{a}>c_{1}^{*}$.

Hence, as long as the biased agent perceives her wealth as larger than its true value, after adjusting the allocation of consumption according to the as-if budget constraint, the biased agent always wants to consume more than the rational agent in the first period (the Appendix contains a detailed proof). Proposition 2 also implies that, if both agents are borrowers in $t=1$, the biased agent borrows more than the rational agent. This is in line with the experimental findings suggesting that biased subjects are more likely to identify themselves as spenders rather than savers and have a lower aversion to debt, compared to unbiased subjects.

PROPOSITION 3 Under the assumption of constant relative risk aversion, and Lemma 1 we have:

$$
\frac{\partial c_{1}^{a}}{\partial y_{1}}>\frac{\partial c_{1}^{*}}{\partial y_{1}}
$$

That is, period- 1 consumption of the biased agent has a positive and more pronounced response to unexpected changes in $y_{1}$ compared to the consumption of the rational agent in the same period (see the proof in the Appendix). This result replicates our experimental finding, as biased subjects report a greater average propensity to consume out of unexpected positive gains compared to unbiased subjects.

\section{C2. Proofs.}

Proof of Proposition 1. By combining the as-if intertemporal budget constraint (16) with condition 18, we can determine adjusted consumption in period one:

$$
c_{1}^{a}=\frac{y_{1}(1+r)-y_{1}^{s}\left(1+r^{s}\right)-\left(y_{2}^{\prime}-y_{2}\right)}{r-r^{s}}
$$

By substituting adjusted consumption in period 1 into the as-if intertemporal budget constraint, we can find the allocation of consumption in period two $\left(c_{2}^{a}\right)$, that is:

$$
c_{2}^{a}=\frac{\left(y_{1}^{s}-y_{1}\right)\left(1+r^{s}\right)(1+r)-y_{2}\left(1+r^{s}\right)+y_{2}^{\prime}(1+r)}{r-r^{s}}
$$

Since $r-r^{s}>0$, then $c_{1}^{a}>0$ when: 


$$
y_{2}^{\prime}<y_{2}+y_{1}(1+r)-y_{1}^{s}\left(1+r^{s}\right)
$$

Moreover, the sparse agent is a borrower if her adjusted allocation is such that in period one she wants to consume more than her wealth, i.e. $c_{1}^{a}>y_{1}$. This is true if:

$$
y_{2}^{\prime}<y_{2}-\left(y_{1}^{s}-y_{1}\right)\left(1+r^{s}\right)
$$

Since $r>r^{s}$, then it follows that condition 24 implies condition 23: trivially, when the sparse agent borrows, her adjusted consumption in period 1 is also positive. So, ultimately, condition 24 guarantees both $c_{1}^{a}>0$ and that the agent is a borrower.

Adjusted consumption in period 2 is positive (i.e. $c_{2}^{a}>0$ ) if:

$$
y_{2}^{\prime}>y_{2} \frac{1+r^{s}}{1+r}-\left(y_{1}^{s}-y_{1}\right)\left(1+r^{s}\right)
$$

Combining conditions 24 and 25, we obtain

$$
y_{2} \frac{1+r^{s}}{1+r}-\left(y_{1}^{s}-y_{1}\right)\left(1+r^{s}\right)<y_{2}^{\prime}<y_{2}-\left(y_{1}^{s}-y_{1}\right)\left(1+r^{s}\right)
$$

This condition identifies the values of $y_{2}^{\prime}$ that guarantee that the biased agent is a borrower, while allowing for positive consumption in the second period.

Proof of Proposition 2. Let us consider the true intertemporal budget constraint (Equation 3) and the as-if intertemporal budget constraint (Equation 14). We report them below for the reader convenience:

$$
\begin{aligned}
c_{1}+\frac{c_{2}}{1+r} & =y_{1}+\frac{y_{2}}{1+r} \\
c_{1}^{a}+\frac{c_{2}^{a}}{1+r^{s}} & =y_{1}^{s}+\frac{y_{2}^{\prime}}{1+r^{s}}
\end{aligned}
$$

By substituting for $c_{2}$ and $c_{2}^{a}$ from the Euler equations of the rational agent and the sparse agent (after adjusting consumption) and taking the difference at both sides at the optimum, we 
get:

$$
c_{1}^{a}-c_{1}^{*}=y_{1}^{s}-y_{1}+\frac{y_{2}^{\prime}}{1+r^{s}}-\frac{y_{2}}{1+r}-\frac{U^{\prime}-1\left[\frac{U_{c_{1}^{a}}^{\prime}}{\beta\left(1+r^{s}\right)}\right]}{1+r^{s}}+\frac{U^{\prime}-1\left[\frac{U_{c_{1}^{*}}^{\prime}}{\beta(1+r)}\right]}{1+r}
$$

Therefore, in order to compare $c_{1}^{a}$ and $c_{1}^{*}$, we assume a Constant Relative Risk Aversion (CRRA) utility function. 37 Let us rewrite the optimization problem for the two agents.

$$
\max U\left(c_{1}, c_{2}\right)=\frac{c_{1}^{1-\varepsilon}}{1-\varepsilon}+\beta \frac{c_{2}^{1-\varepsilon}}{1-\varepsilon}
$$

s.t.

$$
c_{2}=\left(1+r^{s}\right)\left(y_{1}^{s}-c_{1}\right)+y_{2}
$$

Where $y_{1}=\hat{y}_{1}+N, N=A-D$.

The optimization problem yields the following Euler Equation:

$$
c_{1}^{*}=\left[\frac{1}{\beta(1+r)}\right]^{\frac{1}{\varepsilon}} c_{2}^{*}
$$

By making use of the Euler equation and the intertemporal budget constraint, we determine the rational agent's optimal allocation of consumption in both periods:

$$
\begin{aligned}
c_{1}^{*} & =\frac{1}{1+\beta^{\frac{1}{\varepsilon}}(1+r)^{\frac{1-\varepsilon}{\varepsilon}}}\left(y_{1}+\frac{y_{2}}{1+r}\right) \\
c_{2}^{*} & =\frac{[\beta(1+r)]^{\frac{1}{\varepsilon}}}{1+\beta^{\frac{1}{\varepsilon}}(1+r)^{\frac{1-\varepsilon}{\varepsilon}}}\left(y_{1}+\frac{y_{2}}{1+r}\right)
\end{aligned}
$$

The biased agent, solves the same problem but she uses perceived wealth $\left(w^{s}\right)$. Hence:

\footnotetext{
${ }^{37}$ Notice that such specification is in line with our experimental results. In fact, we do not find any correlation between the existence of the bias and agents' risk attitudes.
} 


$$
\max U\left(c_{1}, c_{2}\right)=\frac{c_{1}^{1-\varepsilon}}{1-\varepsilon}+\beta \frac{c_{2}^{1-\varepsilon}}{1-\varepsilon}
$$

s.t.

$$
c_{2}=\left(1+r^{s}\right)\left(y_{1}^{s}-c_{1}\right)+y_{2}^{\prime}
$$

The solution to the optimal consumption choice problem above gives the following Euler equation:

$$
c_{1}^{s}=\left[\frac{1}{\beta\left(1+r^{s}\right)}\right]^{\frac{1}{\varepsilon}} c_{2}^{s}
$$

By combining the Euler equation and the intertemporal budget constraint, we determine the optimal allocation of consumption in both periods for the sparse agent:

$$
\begin{aligned}
& c_{1}^{s}=\frac{1}{1+\beta^{\frac{1}{\varepsilon}}\left(1+r^{s}\right)^{\frac{1-\varepsilon}{\varepsilon}}}\left(y_{1}^{s}+\frac{y_{2}}{1+r^{s}}\right) \\
& c_{2}^{s}=\frac{\left[\beta\left(1+r^{s}\right)\right]^{\frac{1}{\varepsilon}}}{1+\beta^{\frac{1}{\varepsilon}}\left(1+r^{s}\right)^{\frac{1-\varepsilon}{\varepsilon}}}\left(y_{1}^{s}+\frac{y_{2}}{1+r^{s}}\right)
\end{aligned}
$$

However, the desired optimal allocation for the sparse agent is not feasible, as it exceeds the agent's available resources. The agent, therefore, is smart enough to adjust her allocation of consumption:

$$
\begin{aligned}
c_{1}^{a} & =\frac{1}{1+\beta^{\frac{1}{\varepsilon}}\left(1+r^{s}\right)^{\frac{1-\varepsilon}{\varepsilon}}}\left(y_{1}^{s}+\frac{y_{2}^{\prime}}{1+r^{s}}\right) \\
c_{2}^{a} & =\frac{\left[\beta\left(1+r^{s}\right)\right]^{\frac{1}{\varepsilon}}}{1+\beta^{\frac{1}{\varepsilon}}\left(1+r^{s}\right)^{\frac{1-\varepsilon}{\varepsilon}}}\left(y_{1}^{s}+\frac{y_{2}^{\prime}}{1+r^{s}}\right)
\end{aligned}
$$

As described in Condition 18, the adjusted allocation of consumption corresponds to the value of $y_{2}^{\prime}$ that, given her sparse perception of wealth, allows to exhausts the true budget constraint. In other words, $y_{2}^{\prime}$ guarantees that the budget constraint is hit under the true levels of the interest rate $(r)$ and income in period two $\left(y_{2}\right)$ : 


$$
c_{1}^{a}\left(y_{1}^{s}, r^{s}, y_{2}^{\prime}\right)+\frac{c_{2}^{a}\left(y_{1}^{s}, r^{s}, y_{2}^{\prime}\right)}{1+r}=y_{1}+\frac{y_{2}}{1+r}
$$

Given optimal consumption for both agents determined above, we determine the condition such that the adjusted consumption of the biased agent in period 1 is greater than the optimal consumption of the rational agent in the same period:

$$
c_{1}^{a}>c_{1}^{*} \Longleftrightarrow y_{2}^{\prime}>\frac{\left(1+r^{s}\right)\left[1+\beta^{\frac{1}{\varepsilon}}\left(1+r^{s}\right)^{\frac{1-\varepsilon}{\varepsilon}}\right]}{1+\beta^{\frac{1}{\varepsilon}}(1+r)^{\frac{1-\varepsilon}{\varepsilon}}}\left(y_{1}+\frac{y_{2}}{1+r}\right)-\left(1+r^{s}\right) y_{1}^{s}
$$

In order to find the value of $y_{2}^{\prime}$ that guarantees that condition 37 is satisfied, we substitute for $c_{1}^{a}$ and $c_{2}^{a}$ into 36 :

$$
y_{2}^{\prime}=\frac{(1+r)\left[1+r^{s}+\beta^{\frac{1}{\epsilon}}\left(1+r^{s}\right)^{\frac{1}{\epsilon}}\right]}{1+r+\beta^{\frac{1}{\epsilon}}\left(1+r^{s}\right)^{\frac{1}{\epsilon}}}\left(y_{1}+\frac{y_{2}}{1+r}\right)-\left(1+r^{s}\right) y_{1}^{s}
$$

Given the value of $y_{2}^{\prime}$ in Equation 38, it is trivial to show that, since $r>r^{s}$, the condition in Equation 37 is always satisfied for any $\varepsilon>0$. Hence, $c_{1}^{a}>c_{1}^{*}$ always.

Summing up, by assuming a CRRA utility function, we show that the adjusted optimal consumption choice made by the biased agent leads her to consume a greater share of her wealth in period 1, compared to the rational agent, under the condition in Equation 37.

Proof of Proposition 3. We compute the marginal propensities to consume (out of $y_{1}$ ) in period 1 for the two agents:

$$
\begin{aligned}
\frac{\partial c_{1}^{a}}{\partial y_{1}} & =\frac{1}{1+\beta^{\frac{1}{\epsilon}} \frac{\left(1+r^{s}\right)^{\frac{1}{\epsilon}}}{1+r}} \\
\frac{\partial c_{1}^{*}}{\partial y_{1}} & =\frac{1}{1+\beta^{\frac{1}{\epsilon}} \frac{(1+r)^{\frac{1}{\epsilon}}}{1+r}}
\end{aligned}
$$

Consider Equations 39 and 40. It is trivial to show that, under Lemma 1, the biased agent has a greater propensity to consume out of positive income shocks in period 1 compared to the unbiased agent. 